\title{
Enhanced Sensitivity to Hyperpolarizing Inhibition in Mesoaccumbal Relative to Nigrostriatal Dopamine Neuron Subpopulations
}

\author{
Rahilla A. Tarfa, ${ }^{1,2}$ (Rebekah C. Evans, ${ }^{2}$ and $₫$ Zayd M. Khaliq ${ }^{2}$ \\ ${ }^{1}$ Department of Neuroscience, Brown University, Providence, Rhode Island 02906 and ${ }^{2}$ Cellular Neurophysiology Unit, National Institute of Neurological \\ Disorders and Stroke, National Institutes of Health, Bethesda, Maryland 20892
}

Midbrain dopamine neurons recorded in vivo pause their firing in response to reward omission and aversive stimuli. While the initiation of pauses typically involves synaptic or modulatory input, intrinsic membrane properties may also enhance or limit hyperpolarization, raising the question of how intrinsic conductances shape pauses in dopamine neurons. Using retrograde labeling and electrophysiological techniques combined with computational modeling, we examined the intrinsic conductances that shape pauses evoked by current injections and synaptic stimulation in subpopulations of dopamine neurons grouped according to their axonal projections to the nucleus accumbens or dorsal striatum in mice. Testing across a range of conditions and pulse durations, we found that mesoaccumbal and nigrostriatal neurons differ substantially in rebound properties with mesoaccumbal neurons displaying significantly longer delays to spiking following hyperpolarization. The underlying mechanism involves an inactivating potassium $\left(\mathrm{I}_{\mathrm{A}}\right)$ current with decay time constants of up to $225 \mathrm{~ms}$, and small-amplitude hyperpolarization-activated currents $\left(\mathrm{I}_{\mathrm{H}}\right)$, characteristics that were most often observed in mesoaccumbal neurons. Pharmacological block of $\mathrm{I}_{\mathrm{A}}$ completely abolished rebound delays and, importantly, shortened synaptically evoked inhibitory pauses, thereby demonstrating the involvement of A-type potassium channels in prolonging pauses evoked by GABAergic inhibition. Therefore, these results show that mesoaccumbal and nigrostriatal neurons display differential responses to hyperpolarizing inhibitory stimuli that favors a higher sensitivity to inhibition in mesoaccumbal neurons. These findings may explain, in part, observations from in vivo experiments that ventral tegmental area neurons tend to exhibit longer aversive pauses relative to SNc neurons.

Key words: action potential; dopamine; mesoaccumbal; nigrostriatal; potassium channel

Significance Statement

Our study examines rebound, postburst, and synaptically evoked inhibitory pauses in subpopulations of midbrain dopamine neurons. We show that pauses in dopamine neuron firing, evoked by either stimulation of GABAergic inputs or hyperpolarizing current injections, are enhanced by a subclass of potassium conductances that are recruited at voltages below spike threshold. Importantly, A-type potassium currents recorded in mesoaccumbal neurons displayed substantially slower inactivation kinetics, which, combined with weaker expression of hyperpolarization-activated currents, lengthened hyperpolarization-induced delays in spiking relative to nigrostriatal neurons. These results suggest that input integration differs among dopamine neurons favoring higher sensitivity to inhibition in mesoaccumbal neurons and may partially explain in vivo observations that ventral tegmental area neurons exhibit longer aversive pauses relative to SNc neurons.

\section{Introduction}

Midbrain dopamine neurons contribute to a range of behaviors including reward, aversion, and movement. Early studies classi-

Received Sept. 21, 2016; revised Feb. 2, 2017; accepted Feb. 10, 2017.

Author contributions: R.A.T., R.C.E., and Z.M.K. designed research; R.A.T., R.C.E., and Z.M.K. performed research; R.A.T., R.C.E., and Z.M.K. analyzed data; R.A.T. and Z.M.K. wrote the paper.

This work was supported by NINDS Intramural Research Program Grant NS003134 to Z.M.K. We thank the members of the Khaliq lab for helpful comments throughout the planning and execution stages of this study. We thank Renshu Zhang for the intracranial injections.

The authors declare no competing financial interests. fied dopamine neurons based on their anatomical location within either the ventral tegmental area (VTA) or the substantia nigra (SNc) (Dahlstroem and Fuxe, 1964). However, individual dopamine neurons innervate only a single brain nucleus and thus may be more effectively classified according to their axonal projections (Fallon and Moore, 1978; Oades and Halliday, 1987;

Correspondence should be addressed to Dr. Zayd Khaliq, Cellular Neurophysiology Unit, National Institute of Neurological Disorders and Stroke, National Institute of Health, Bethesda, MD 20892. E-mail: zayd.khaliq@nih.gov. DOI:10.1523/JNEUROSCI.2969-16.2017

Copyright $\odot 2017$ the authors $\quad 0270-6474 / 17 / 373311-20 \$ 15.00 / 0$ 
Björklund and Dunnett, 2007; Aransay et al., 2015). In particular, a subset of VTA dopamine neurons project to the nucleus accumbens (mesoaccumbal), while most $\mathrm{SNc}$ neurons project primarily to the dorsal striatum (nigrostriatal). Determining whether mesoaccumbal and nigrostriatal neurons form functionally distinct subpopulations is an important step in understanding how dopamine-dependent signaling contributes to reward and motor circuits.

Dopamine neurons recorded in vivo pause their firing following reward omission or in response to aversive stimuli (Schultz et al., 1997; Ungless et al., 2004; Fiorillo et al., 2013a,b). Interestingly, the duration of pauses varies with cell location within the midbrain. For example, VTA neurons reliably pause their firing in response to aversive stimuli (Mileykovskiy and Morales, 2011; Wang and Tsien, 2011), while SNc neurons respond more variably with either decreasing or increasing excitability (Matsumoto and Hikosaka, 2009; Lerner et al., 2015) or do not respond at all (Brown et al., 2009). One compared pauses in vivo following spontaneously generated bursts in dopamine neurons, and found that mesoaccumbal neurons exhibited significantly longer postburst pauses than nigrostriatal neurons (Clark and Chiodo, 1988). Although the observed heterogeneity in pauses among dopamine neurons subpopulations likely involves differences in synaptic inputs, whether differences in intrinsic membrane conductances contribute has yet to be fully determined.

Cellular-level studies examining membrane responses to prolonged hyperpolarizations have provided important insight into the ionic conductances that shape the rebound properties of substantia nigra neurons (Neuhoff et al., 2002; Amendola et al., 2012). These studies demonstrate that postinhibitory rebound delays rely on the interplay of transient outward potassium $\left(\mathrm{I}_{\mathrm{A}}\right)$ currents along with hyperpolarization-activated cation $\left(\mathrm{I}_{\mathrm{H}}\right)$ currents. However, whether rebound delays are predictive of responses to inhibitory stimuli that occur at the subthreshold voltages achieved during natural spontaneous activity is not well understood. Furthermore, experiments testing the intrinsic conductances that shape synaptically evoked inhibitory (i.e., GABAergic) pauses in dopamine neurons have not yet been performed, and whether these underlying ionic conductances differ between mesoaccumbal and nigrostriatal dopamine neuron subpopulations is not well understood.

We used retrograde labeling and electrophysiology in combination with computational modeling to compare rebound properties, postburst pauses and synaptically evoked inhibitory pauses in mesoaccumbal and nigrostriatal dopamine neuron subpopulations. We found that mesoaccumbal neurons exhibit substantially longer rebound delays than nigrostriatal neurons in response to hyperpolarizing current injections covering a range of amplitudes and durations. Recording the underlying ionic currents in voltage-clamp mode, we found that the higher sensitivity of mesoaccumbal neurons relies on recruitment of A-type potassium currents that display slow inactivation kinetics. By contrast, nigrostriatal neurons expressed $\mathrm{I}_{\mathrm{A}}$ currents that displayed faster inactivation kinetics and larger amplitude $\mathrm{I}_{\mathrm{H}}$ currents. Computational modeling demonstrated that the slow decay of $\mathrm{I}_{\mathrm{A}}$ alone slows rebound responses to hyperpolarizing inhibition, even in the presence of sizeable $\mathrm{I}_{\mathrm{H}}$ and T-type calcium currents. Last, we tested the pharmacological block of $\mathrm{I}_{\mathrm{A}}$ on pauses evoked by GABAergic synaptic inputs and found that $\mathrm{I}_{\mathrm{A}}$ enhances GABAmediated pauses in dopamine neurons. Together, these experiments demonstrate that mesoaccumbal and nigrostriatal neurons display differential responses to hyperpolarizing inhibition. Furthermore, a unique combination of ionic conductances in mesoaccumbal neurons prolong pauses in firing and may consequently play an important role in signaling of aversive events. Given recent findings that dopamine neuron subpopulations receive largely overlapping synaptic inputs (Beier et al., 2015; Lerner et al., 2015; Menegas et al., 2015), these results suggest that heterogeneity in intrinsic and integrative properties are equally important contributors to functional diversity among dopamine neuron subpopulations.

\section{Materials and Methods}

Animal husbandry. Experiments were performed on transgenic male and female mice (postnatal day 14 to 23) in which the expression of the green fluorescent protein (GFP) is driven by the promotor for tyrosine hydroxylase (TH-GFP mice) (Matsushita et al., 2002). All mice were maintained according to the guidelines set by the Animal Care and Use Committee for the National Institute of Neurological Disorders and Stroke and the National Institutes of Health.

Stereotaxic Brain Injections. A Stoelting stererotaxic instrument for small animals was used to microinject the retrograde labeler choleratoxin subunit B (CTB) conjugated to Alexa-555 (CTB-AF555) into the left and right hemispheres of TH-GFP mice at postnatal days 15 to 18 . Mice were anesthetized using 1.5\% isoflourane. Each scalp was shaved, cleaned with betadine and saline, injected with lidocaine (1\%), and incised. PBS was used to keep the skull moist throughout surgery. The coordinates which correspond to bregma, lateral and ventral respectively were as follows: $\pm 1.6, \pm 1.5,-4.6$ for nucleus accubens and $\pm 1.6, \pm 1.4$, -2.5 for the dorsal striatum. CTB-AF555 $(<0.8 \mu \mathrm{l})$ was injected using a Hamilton microsyringe. After surgery, the scalp wound was closed using vet bond glue and the mouse was placed in an aerated cage to recover before being placed back in cage with parents and littermates. Mice were used for electrophysiology after a minimum of $3 \mathrm{~d}$.

Slice preparation. Coronal midbrain slices of $300 \mu \mathrm{m}$ thickness were prepared from TH-GFP mice using a Microslicer DTK-Zerol. Slices were cut in an ice-cold glycerol-based slicing solution containing the following (in mM): 250 glycerol, $2.5 \mathrm{KCl}, 2 \mathrm{MgCl}_{2}, 2 \mathrm{CaCl}_{2}, 1.2 \mathrm{NaH}_{2} \mathrm{PO}_{4}, 10$ HEPES, $21 \mathrm{NaHCO}_{3}$, and 5 glucose. Slices were incubated in a warm $33^{\circ} \mathrm{C}$ bath containing recording solution simultaneously bubbled with $95 \% \mathrm{O}_{2} / 5 \% \mathrm{CO}_{2}$ for $30 \mathrm{~min}$ and incubated at room temperature for another $30 \mathrm{~min}$. Recording solution contained the following (in $\mathrm{mM}$ ): $125 \mathrm{NaCl}, 25 \mathrm{NaHCO}_{3}, 1.25 \mathrm{NaH}_{2} \mathrm{PO}_{4}, 3.5 \mathrm{KCl}, 10$ glucose, 5 HEPES, 1 $\mathrm{MgCl}_{2}$, and $2 \mathrm{CaCl}_{2}$.

Patch-clamp electrophysiology. Midbrain slices containing the VTA and $\mathrm{SNc}$ were placed in a heated recording chamber that was continuously perfused with heated ACSF with temperatures ranging from 31 to $33^{\circ} \mathrm{C}$. Candidate neurons were first visualized and located using an upright Olympus BX50WI microscope connected to a Hamamatsu CCD camera. GFP-positive green neurons were considered to be dopamine neurons and CTB-AF555 positive red neurons were identified as retrogradelylabeled subpopulations that innervate either nucleus accumbens or dorsal striatum. Neurons were recorded only if they were positive for both red and green fluorescence, indicating that they were dopamine neurons that projected to the either the nucleus accumbens or dorsal striatum.

Neurons were recorded using borosilicate recording electrodes (VWR International) pulled using a flaming/brown micropipette puller (Sutter Instrument). Pipettes were filled with an internal recording solution that contained the following (in mM): $135 \mathrm{KMeSO}_{3}, 10 \mathrm{NaCl}, 10 \mathrm{HEPES}, 2$ $\mathrm{MgCl}_{2}, 0.5 \mathrm{EGTA}$, and $0.1 \mathrm{CaCl}_{2}$. Electrodes were wrapped with Parafilm to reduce electrode capacitance. Brain slices were placed in a recording chamber that was constantly perfused with oxygenated recording solution. Slices were visualized with an upright microscope (Olympus) via an IR-DIC prism with $4 \times$ and $60 \times$ objectives. All data were collected using pClamp10 software (Molecular Devices), recorded on a Multiclamp $700 \mathrm{~B}$ amplifier, and digitized on a Digidata 700B. Data were filtered at 10 $\mathrm{kHz}$ and sampled at $20 \mathrm{kHz}$. Series resistance and whole-cell capacitance were compensated using the whole-cell and $R_{\mathrm{s}}$ compensation features and $R_{\mathrm{s}}$ monitored frequently. Cells with uncompensated series resistances of $>16 \mathrm{M} \Omega$ were immediately discarded. All experiments were performed at $31-33^{\circ} \mathrm{C}$. 
Spontaneous and evoked firing. To maximize the number of recordings displaying healthy firing activity, spontaneous firing was first monitored for a period in a cell-attached configuration. The membrane was then ruptured while recording in current-clamp mode, which allowed for easy identification of firing rate changes due to damage during breakthrough. Initial spontaneous firing activity was obtained for 1-2 min, during which the health of the neuron was further evaluated. If the spontaneous firing rate differed dramatically from the firing rate during the cellattached configuration, the cell was discarded. Bridge balance was often corrected using the automatic function of the Multiclamp amplifier. Frequency-intensity curves were obtained for each neuron by providing a series of depolarizing current injections ( $40 \mathrm{pA}$ steps, $1 \mathrm{~s}$ duration) during their spontaneous activity. The maximal firing rate taken as the rate immediately preceding entry into depolarization block.

Voltage-clamp recordings. A-type potassium currents $\left(\mathrm{I}_{\mathrm{A}}\right)$ were isolated pharmacologically using extracellular recording solutions that included $50 \mathrm{~mm}$ tetraethylammonium chloride (TEA-Cl) and $1 \mu \mathrm{M}$ TTX. In some instances, $30 \mu \mathrm{M}$ nifedipine, $20 \mu \mathrm{M}$ ZD9866, $100 \mu \mathrm{M}$ 4-aminopyridine, and $3 \mu \mathrm{M}$ cesium chloride were present. A-type potassium currents exhibiting both the slow and fast inactivation kinetics were blocked in the presence of either 0.5 or $1 \mu \mathrm{M}$ AmmTX3 (a specific blocker for $\mathrm{K}_{\mathrm{v}} 4$ channels). The time constant of inactivation was measured in currents evoked by steps from -90 to $-40 \mathrm{mV}$. The voltage dependence of inactivation was tested using a pulse to $-40 \mathrm{mV}(250 \mathrm{~ms})$ preceded by family of prepulse voltage steps $(1 \mathrm{~s})$ ranging from -120 to $-40 \mathrm{mV}$.

Histology and confocal imaging. Slices with retrogradely labeled dopamine neurons were placed in $4 \%$ paraformaldehyde for at least $24 \mathrm{~h}$ and rinsed three times with PBS before being mounted onto glass slides with mounting medium (Vectashield). In Figure 1, slices were imaged using a Leica microscope with an inverted $10 \times$ objective. In Figure 2, neurons were imaged using a laser scanning confocal LSM 510 microscope using an inverted $10 \times$ objective for images of the whole tissue depicting injection site and $63 \times$ for the individual neuron (Fig. 2). Images were processed using Image $(\mathrm{NIH})$.

Data analysis and statistics. All electrophysiological traces were analyzed using Igor (Wavemetrics). To quantify voltage dependence of inactivation, current amplitudes resulting from a test pulse to $-40 \mathrm{mV}$ were plotted against prepulse voltages. Values were then fit with the following Boltzmann function: $f(x)=I_{\max } *\left[1 /\left(1+\exp \left[\left(x-V_{\mathrm{h}}\right) / k\right]\right)\right]+I_{\min }$, where $I_{\max }$ equals maximal current, $V_{\mathrm{h}}$ equals the voltage of half-inactivation, $k$ equals the slope factor, and $I_{\min }$ equals the minimal current. Recovery from inactivation was obtained by plotting the ratio of the amplitudes of the second pulse (test) to the first pulse to the time interval. The curve was fit to a rising exponential function to obtain the time constant of recovery from inactivation.

To calculate the recovery from inactivation, the fraction of recovery was calculated as the ratio of the recovered current amplitude to the amplitude of the test pulse. The fraction of recovery was then plotted against the corresponding duration of the recovery step between pulses and fit with an exponential to obtain the recovery time constant.

The junction potential of our methanesulfonate-based internal solution was measured at $-8.2 \mathrm{mV}$; however, the data presented were not corrected. All statistics were performed using either the nonparametric tests, Mann-Whitney $U$ test, or Student's $t$ test except where noted. Average values are reported as means \pm SEM.

Computational modeling. A computational model of a VTA dopamine neuron was created in Genesis simulation software (Bower and Beeman, 2007). This model contains a fast sodium current $\left(\mathrm{Na}_{\mathrm{f}}\right.$; Seutin and Engel, 2010; Tucker et al., 2012), a sodium leak current $\left(\mathrm{Na}_{\mathrm{L}}\right)$, a delayed rectifying potassium current (Liu et al., 2012; Khaliq and Bean, unpublished data), an A-type potassium current $\mathrm{I}_{\mathrm{A}}$, an $\mathrm{I}_{\mathrm{H}}$ current (Z. M. Khaliq, unpublished data; Migliore et al., 2008), and the calcium-activated potassium channels, SK and BK (Hirschberg et al., 1998; Maylie et al., 2004; Evans et al., 2013; Jaffe et al. 2011). In addition, the model contains five calcium channels (T, R, N, $\mathrm{L}_{1.2}$, and $\mathrm{L}_{1.3}$; Tuckwell, 2012; Evans et al., 2013; Table 1). All calcium channels contribute to a calcium pool, modeled with a single time constant of decay $(25 \mathrm{~ms})$, which activates the SK and BK channels. The computational model has a spherical soma with two symmetrical primary dendrites which branch into secondary and tertiary dendrites, each dendrite is broken into compartments of $20 \mu \mathrm{m}$ each for a total of 69 compartments (including soma). All channels are the same density throughout compartments, except the A-type potassium current, which is limited to the soma and proximal dendrites $(<50$ $\mu \mathrm{m}$ from the soma) to replicate (Gentet and Williams, 2007), and the T-type current, which is located only in the dendrites. The model was tuned to replicate the slow $(1-5 \mathrm{~Hz})$ spontaneous firing rate and high input resistance characteristic of dopamine neurons. Voltage-clamp simulations were conducted in a single somatic compartment. The computational model will be made available on ModelDB. Please see Table 1 below for a summary of the conductances used in the model.

\section{Results}

Similar postburst pauses but larger rebound delays in mesoaccumbal vs nigrostriatal dopaminergic neurons

Dopaminergic neurons recorded in vivo pause their firing in response to aversive stimuli (Ungless et al., 2004; Matsumoto and Hikosaka, 2009) and reward omission (Schultz et al., 1997; Cohen et al., 2012). Past work analyzing spontaneous burst-pause activity recorded in anesthetized rats reported substantially longer postburst pauses in mesoaccumbal neurons compared to the nigrostriatal neurons (Clark and Chiodo, 1988). However, whether differences in intrinsic properties can account for the distinctly longer burstpauses reported in mesoaccumbal neurons has yet to be determined. Therefore, we first compared postburst pauses recorded in midbrain dopamine neurons categorized according to their axonal projections to either nucleus accumbens (mesoaccumbal) or dorsal striatum (nigrostriatal) dopamine subpopulations.

To visually identify dopamine neurons projecting to distinct brain regions, we injected CTB-AF555 into either the nucleus accumbens or dorsal striatum of mice that express GFP driven by the tyrosine hydroxylase promoter (TH-GFP; Matsushita et al., 2002; Fig. 1). Injections into the nucleus accumbens resulted in a majority of labeled neurons located in the ventral tegmental area (Fig. 1A-C). While most dual labeled neurons were present in VTA, many could be found at the border of VTA and SNc with occasional neurons found in the SNc. Similarly, we found that CTB injections into the dorsal striatum resulted in dual labeled neurons in the SNc with a number of neurons found at the border of SNc and VTA (Fig. 1D-F). Because the borders of these two nuclei (SNc and VTA) are not well defined and contain mixtures of mesoaccumbal and nigrostriatal neurons, retrograde labeling of dopamine neuron subpopulations was necessary for clear identification of cell types. Therefore, whole-cell recordings were made only from neurons colabeled with GFP and CTB-AF555, indicating projection-specific dopamine neuron subpopulations.

To test postburst pauses, we interrupted spontaneous firing with $1 \mathrm{~s}$ depolarizing current pulses covering a range of amplitudes to evoke high-frequency firing, and then measured the subsequent postbust pause (Fig. $2 C, D$ ). We found that the rates of spontaneous firing in mesoaccumbal and nigrostriatal neurons were comparable at $2.89 \pm 0.14 \mathrm{~Hz}(n=89)$ versus $2.43 \pm 0.14$ $\mathrm{Hz}(n=72$; Mann-Whitney test, $p=0.03)$ but statistically different. Comparing burst pauses at maximal firing rates, we found that mesoaccumbal dopamine neurons exhibited substantially higher maximal firing rates at $20.36 \pm 1.54 \mathrm{~Hz}$, resulting in longer postburst pauses of $1.92 \pm 0.18 \mathrm{~s}(n=28)$ relative to nigrostriatal neurons, which fired maximally at $13.18 \pm 0.8 \mathrm{~Hz}$, resulting in an average postburst pause of $1.3 \pm 0.09 \mathrm{~s}(n=36)$. However, when comparing pauses following bursting at similar rates, we found that the duration of postburst pauses was similar between mesoaccumbal and nigrostriatal neurons (Fig. 2D). In contrast to previous work in vivo (Clark and Chiodo, 1988), we found that 

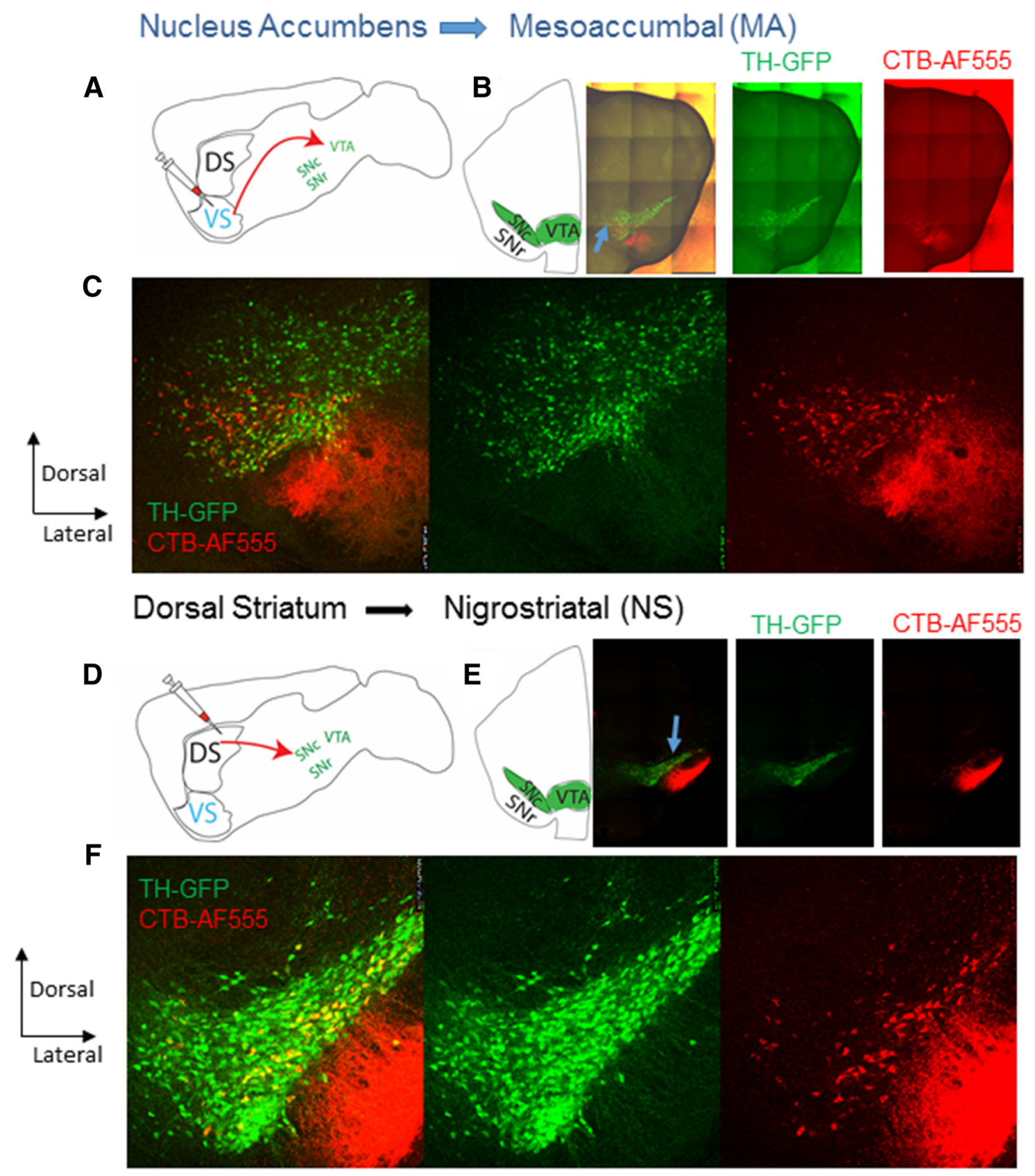

Figure 1. Retrograde labeling of mesoaccumbal and nigrostriatal dopamine neurons. $A$, Schematic of a sagittal section of a mouse brain along with mesoaccumbal projection. CTB conjugated to Alexa555 was injected into nucleus accumbens to retrogradely label dopamine neurons in the VTA. B, Schematic (left) and 10X tiled image of a coronal section of midbrain slice (right) in TH-GFP mouse depicting mesoaccumbal subpopulations. GFP-positive TH cells are show in green, and CTB-positive NAc-projecting neurons are shown in red. C, Image of VTA and SNc demonstrating the mesoaccumbal subpopulation. $\boldsymbol{D}$, Schematic of injection site of CTB in the dorsal striatum. $\boldsymbol{E}$, Schematic (left) and $10 \times$ tiled image (right) of a coronal section of midbrain slice in same TH-GFP mouse depicting nigrostriatal subpopulation. $\boldsymbol{F}$, Image of the VTA (medial) and SNc (lateral). DS, Dorsal striatum; VS, ventral striatum.

the intrinsically generated postburst pauses do not differ between mesoaccumbal and nigrostriatal neurons.

A separate variety of pauses occurs as a result of stimuli that directly inhibit firing, such as those originating from activation of inhibitory $\mathrm{GABA}_{\mathrm{A}}$ mediated inputs (Tepper and Lee, 2007), or from activation of hyperpolarizing modulatory receptors such as $\mathrm{GABA}_{\mathrm{B}}$ receptors (Edwards et al., 2017) or dopamine $\mathrm{D}_{2}$ autoreceptors (Gantz et al., 2013). To gain insight into the intrinsic cell properties that contribute to pauses resulting from hyperpolarizing inhibition, we next examined rebound properties of dopamine neurons. We interrupted spontaneous firing with a range of hyperpolarizing current injections and measured the latency to the first spike as the cell resumed firing, hereafter called the "rebound delay" (Fig. $2 E, F, I$ ). We then plotted the rebound delay against the cell's voltage measured at the point that the current injection was released, referred to as the "baseline voltage" (Fig. $2 F, I)$. There was substantial variability within dopamine neuron subpopulations, with rebound delays ranging from $128.8 \mathrm{~ms}$ to $1.3 \mathrm{~s}$ in mesoaccumbal neurons and 99 to $882.9 \mathrm{~ms}$ in nigrostriatal neurons (measured from a baseline of $-65 \mathrm{mV}$ to $-75 \mathrm{mV}$; Fig. $2 I, J)$. Interestingly, however, the average duration of rebound delays were twice as long in mesoaccumbal neurons as compared to nigrostriatal neurons (maximal rebound delays at $-75 \mathrm{mV}$, mesoaccumbal, $650.8 \pm 100.83 \mathrm{~ms}, n=24$; nigrostri- 
A

Mesoaccumbal (MA)

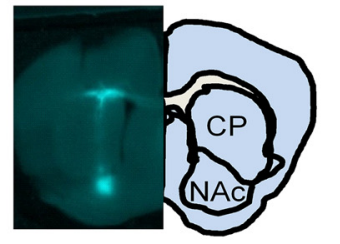

C

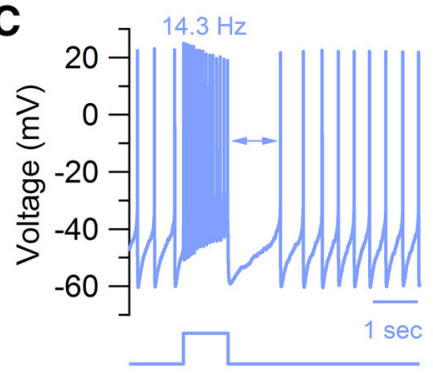

E

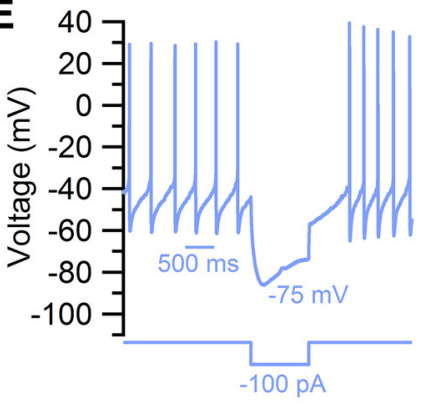

G
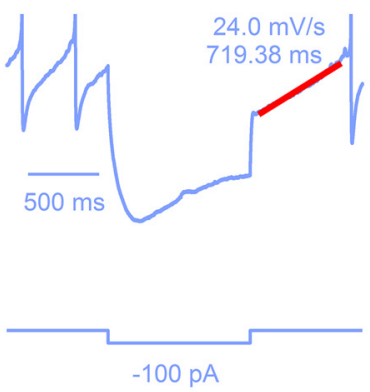

I

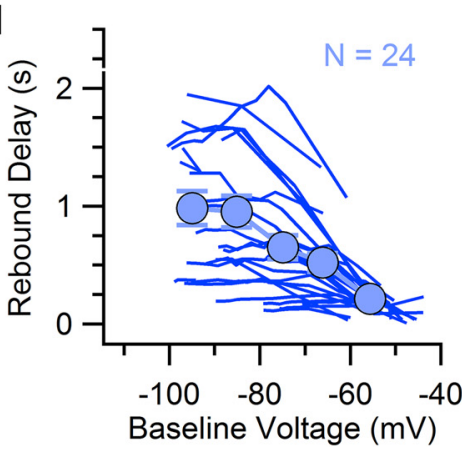

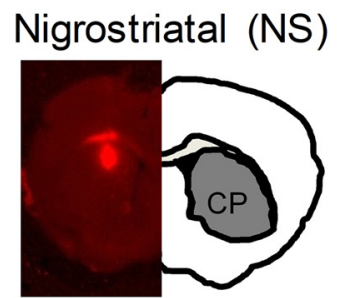
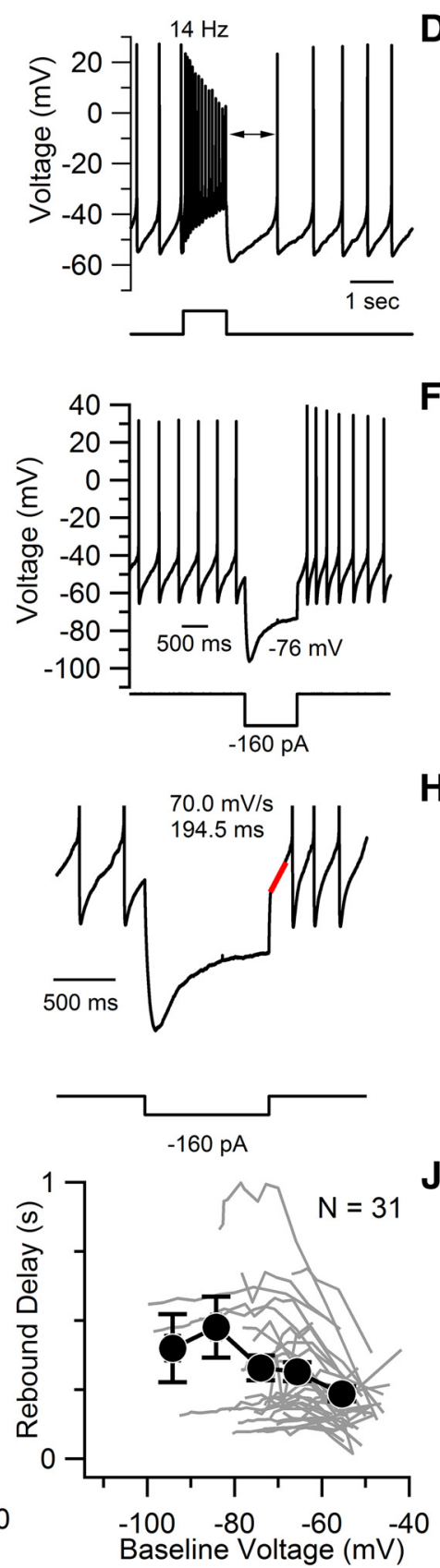

D

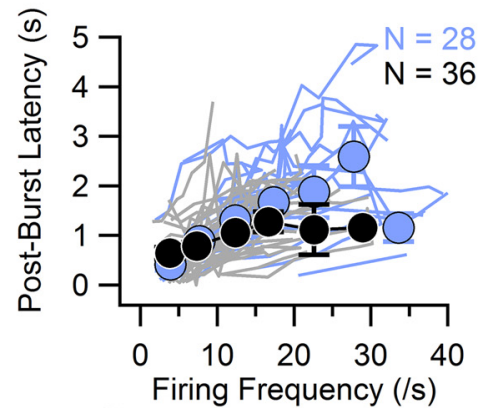

B

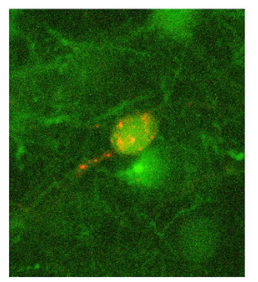

TH-GFP

CTB-AF555

$\mathbf{F}$

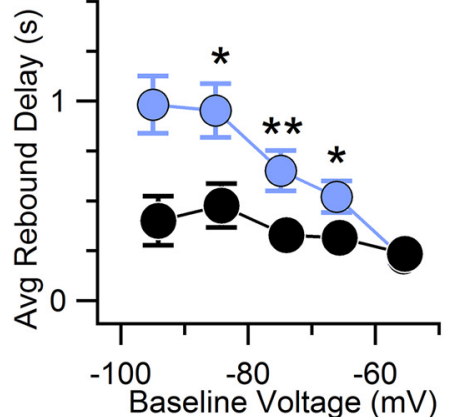

H

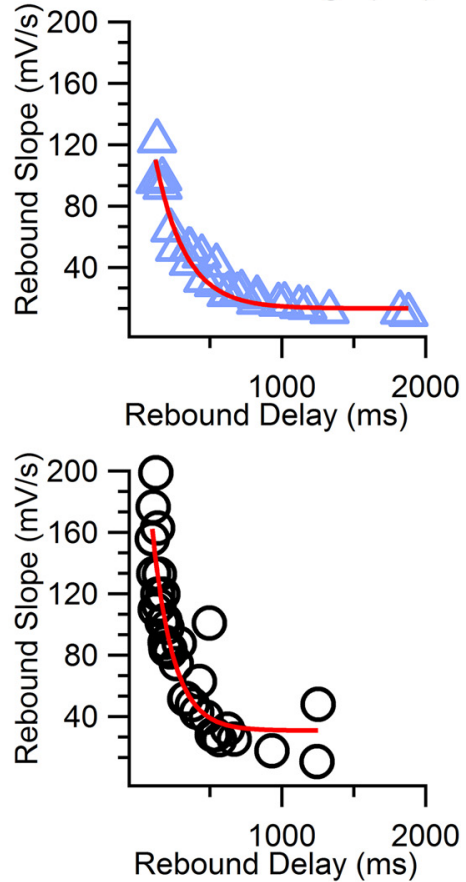

Baseline Voltage $(\mathrm{mV})$

Figure 2. Comparison of postburst pauses and rebound delays in mesoaccumbal and nigrostriatal dopamine subpopulations. $\boldsymbol{A}$, Injection site of CTB in the nucleus accumbens (left) and dorsal striatum (right) of a TH-GFP mouse. $\boldsymbol{B}$, Example of TH-GFP + dopamine neuron retrogradely labeled with CTB-AF555 injected into nucleus accumbens. $\boldsymbol{C}$, Example traces in which spontaneous firing recorded in mesoaccumbal (blue) and nigrostriatal (black) neurons has been interrupted with a depolarizing current injection. Arrows indicate postburst latency. $\boldsymbol{D}$, Plot of averaged binned postburst latency versus burst frequency in mesoaccumbal and nigrostriatal dopamine neurons. Closed symbols represent the mean \pm SEM. Lines represent data from individual neurons (blue, mesoaccumbal; gray, nigrostriatal). $\boldsymbol{E}$, Example traces of rebound delays from mesoaccumbal (blue) and nigrostriatal (black) in response to a $1 \mathrm{~s}$ hyperpolarizing current injection. Baseline voltage values are indicated. $\boldsymbol{F}$, Plot of averaged binned maximal rebound delays versus baseline voltage. $\boldsymbol{G}$, Examples of rebound delays shown on an expanded scale for clarity showing linear fit of the rebound delay (red lines) as a measure of the rebound slope. $\boldsymbol{H}$, Plot of rebound slope versus rebound delay in mesoaccumbal dopamine neurons (triangles) measured from a baseline voltage of $\sim-75 \mathrm{mV}$. The red line indicates exponential fit. $I$, Summary of rebound pause duration in mesoaccumbal neurons (left). Dark blue lines show individual neurons ( $N=24$ ), and light blue circles show $5 \mathrm{mV}$ binned averages \pm SEM. A summary of nigrostriatal neurons is shown on the right. Gray lines show individual neurons $(N=31)$, and black circles and lines show $5 \mathrm{mV}$ binned averages $\pm \mathrm{SEM}$. $J$, Same plot as in $\boldsymbol{H}$ but in nigrostriatal dopamine neurons (circles). The red line indicated exponential fit. Asterisks indicate a $P$ value $<0.05$. 
Table 1. Conductance and permeability values for the dopamine neuron model

\begin{tabular}{|c|c|c|c|}
\hline Channel & Soma & Proximal $(<51 \mu \mathrm{m})$ & Distal $(>51 \mu \mathrm{m})$ \\
\hline \multicolumn{4}{|l|}{$\operatorname{Gbar}\left(S / m^{2}\right)$} \\
\hline $\mathrm{Na}$ & 250 & 250 & 250 \\
\hline $\mathrm{Na}$ (leak) & 0.135 & 0.135 & 0.135 \\
\hline $\mathrm{K}_{\mathrm{DR}}$ & 20 & 20 & 20 \\
\hline SK & 3 & 3 & 3 \\
\hline BK & 500 & 500 & 500 \\
\hline IH & $0.5,1$, or $3^{a}$ & $0.5,1$, or $3^{a}$ & $0.5,1$, or $3^{a}$ \\
\hline KA & 24.5 to $32^{a}$ & 24.5 to $32^{a}$ & 0 \\
\hline \multicolumn{4}{|l|}{$\operatorname{Pbar}(\mathrm{cm} / \mathrm{s})$} \\
\hline Ca-R type & $0.5 e-6$ & $0.5 e-6$ & $0.5 e-6$ \\
\hline $\mathrm{Ca}-\mathrm{N}$ type & $1.2 \mathrm{e}-6$ & $1.2 \mathrm{e}-6$ & $1.2 \mathrm{e}-6$ \\
\hline Ca-L type (1.2) & $0.1 e-6$ & $0.1 e-6$ & $0.1 e-6$ \\
\hline Ca-L type (1.3) & $5 e-9$ & $5 e-9$ & $5 e-9$ \\
\hline Ca-T type & 0 & $0.1 \mathrm{e}-6$ or $1 \mathrm{e}-6^{a}$ & $0.1 \mathrm{e}-6$ or $1 \mathrm{e}-6^{a}$ \\
\hline
\end{tabular}

${ }^{a}$ Conductances and permeabilities are altered as indicated in Figure 11.

atal, $327.8 \pm 44.6 \mathrm{~Hz}, n=31$; Mann-Whitney test, $p=0.0038$; Fig. $2 F$ ). As a complementary measurement of the delay, we measured the depolarizing slope of the membrane potential during the rebound delay, called the "rebound slope." We found that a plot of the rebound slope against the rebound delay was fit well by an exponential function in both the mesoaccumbal and nigrostriatal subpopulations (Fig. $2 \mathrm{H}, \mathrm{J}$ ). In particular, we found that steeper rebound slopes and, by consequence, faster rebound delays were more likely present in the nigrostriatal dopamine neurons. Together, our results show that mesoaccumbal and nigrostriatal neurons exhibit similar spontaneous activity and postburst pauses, but display divergent responses to hyperpolarization as shown in the differences in their rebound properties.

\section{Development of rebound delays evoked by a range of brief duration hyperpolarizations}

We next quantified the dependence of the rebound delay on the duration of the hyperpolarizing current for injections ranging from 1 to $500 \mathrm{~ms}$. An example recording from a mesoaccumbal neuron is provided in Figure $3 A$. We found that brief hyperpolarization durations of 1,5 , or $10 \mathrm{~ms}$ had little effect on the timing of subsequent spikes. However, longer hyperpolarizations of 25 $\mathrm{ms}$ and above resulted in substantial increases in rebound delays, with the maximal rebound delay of $711.9 \mathrm{~ms}$ occurring in response to a $100 \mathrm{~ms}$ hyperpolarization. Longer hyperpolarizations $(>100 \mathrm{~ms})$ produced no further enhancement of the delay. Similarly, in the example nigrostriatal neuron shown in Figure $3 B$, a hyperpolarization of $100 \mathrm{~ms}$ resulted in a maximal delay of only $266.2 \mathrm{~ms}$. We observed the same trend across a population of cells (Fig. 3C,D). Mesoaccumbal neurons displayed average maximal rebound delays of $1207 \pm 186 \mathrm{~ms}(n=16)$ with 14 of 16 cells achieving maximal delays following hyperpolarizing pulses of $100 \mathrm{~ms}$. In nigrostriatal neurons, maximal delays were achieved with following hyperpolarizing pulses of $50 \mathrm{~ms}$ in 2 neurons, 100 $\mathrm{ms}$ in 4 neurons, and $500 \mathrm{~ms}$ in 1 neuron. Among these neurons, the duration of the maximal rebound delay was an average of $578.12 \pm 93.65 \mathrm{~ms}(n=7$; Mann-Whitney test, $p=0.047)$. Therefore, although mesoaccumbal and nigrostriatal neurons differ in the duration of their maximal delays, these results demonstrate that an initial hyperpolarization of $\sim 100 \mathrm{~ms}$ in duration is sufficient to reach maximal rebound delay in both cell types.

\section{Effect of subthreshold inhibitory current pulses on spike timing during pacemaking}

Long-duration, severe hyperpolarizations are typically used to evoke rebound delays. Although convenient experimentally, these hyperpolarizations may recover channels that would have been otherwise inactivated and may exaggerate the contribution of these conductances to excitability within the physiological voltage range. Therefore, we focused on firing responses to short hyperpolarizations $(5,25$, and $100 \mathrm{~ms})$ designed to mimic activity from a single input or short summating bursts of hyperpolarizing inhibitory inputs. To test this, we injected hyperpolarizing current injections of increasing amplitudes on a background of spontaneous firing activity. Figure $4 A$ provides the layout of the experiment wherein increasing amplitudes of current injections that lasted 5, 25, and $100 \mathrm{~ms}$ were injected, interleaved by spontaneous firing activity in both mesoaccumbal and nigrostriatal dopamine neurons. Figure $4, B$ and $C$, provides typical responses to $100 \mathrm{~ms}$ current injections in mesoaccumbal and nigrostriatal neurons. A current injection that hyperpolarized neurons to near $-55 \mathrm{mV}$ resulted in a $294.8 \mathrm{~ms}$ delay in the mesoaccumbal neuron, but only slightly shorter delay of $285.2 \mathrm{~ms}$ in the nigrostriatal neuron. Further hyperpolarization to near $-65 \mathrm{mV}$, however, resulted in a delay of $522.6 \mathrm{~ms}$ in mesoaccumbal neurons, but a somewhat shorter delay of $420.22 \mathrm{~ms}$ in the nigrostriatal neuron.

We next quantified the effect of brief current injections on spike timing. To do this, we normalized the duration of the interspike interval affected by the current injection $\left(\mathrm{ISI}_{0}\right)$ to the preceding interspike interval during spontaneous firing $\left(\mathrm{ISI}_{1}\right)$, calculated as the $\mathrm{ISI}_{1} / \mathrm{ISI}_{0}$ ratio (Fig. $4 \mathrm{~B}, \mathrm{C}$ ). To robustly compare effects across neurons and reduce variability in the timing of the onset of the current injections, we analyzed injections that occurred only within the middle $50 \%$ of the interspike interval (ISI). In our example cells, hyperpolarizing to a minimum voltage of $-65 \mathrm{mV}$ for $100 \mathrm{~ms}$ in the mesoaccumbal neuron resulted in a $\mathrm{ISI}_{1} / \mathrm{ISI}_{0}$ ratio of 2.10 , an increase of more than double the duration of the control interspike interval. In the nigrostriatal neuron, however, we observed a ISI ${ }_{1} / \mathrm{ISI}_{0}$ ratio of only 1.5 , a $50 \%$ increase in the interspike interval.

In a population of cells, we plotted the $\mathrm{ISI}_{1} / \mathrm{ISI}_{0}$ ratio against the minimum voltage reached following the hyperpolarizing current injection. We reasoned that plotting the minimum voltage should control for potential differences in input resistance between cell types. Following $100 \mathrm{~ms}$ current injections that hyperpolarized cells to $-55 \mathrm{mV}$, we found an $\mathrm{ISI}_{1} / \mathrm{ISI}_{0}$ ratio of $1.71 \pm$ 0.08 , a $70.8 \%$ increase in the interspike interval of mesoaccumbal neurons $(n=16)$, compared to an $\mathrm{ISI}_{1} / \mathrm{ISI}_{0}$ ratio of $1.44 \pm 0.09$, an increase of the $44 \%$ in nigrostriatal neurons $(n=8 ; p=0.048$; Fig. $4 F$ ). With further membrane hyperpolarization to $-65 \mathrm{mV}$, well within physiological voltage range in dopamine neurons, the difference between $\mathrm{ISI}_{1} / \mathrm{ISI}_{0}$ ratios measured in mesoaccumbal and nigrostriatal neurons became more prominent. The ISI ${ }_{1} / \mathrm{ISI}_{0}$ ratio following hyperpolarization to $-65 \mathrm{mV}$ in mesoaccumbal neurons was $2.36 \pm 0.1$, an increase in duration of $136 \%$, and in nigrostriatal neurons it was $166.2 \pm 0.04$, an increase in duration of $66.2 \%(n=8 ; p=3.2 \mathrm{e}-7)$. Probing the response to 5 and $25 \mathrm{~ms}$ hyperpolarizations, however, we found no difference in the ISI 1 $\mathrm{ISI}_{0}$ ratio between subpopulations at any voltage measured (Fig. 4D,E). Collectively, these data demonstrate that mesoaccumbal and nigrostriatal neurons differ substantially in their sensitivity to both long (1 s) and short (100 ms) hyperpolarizing inputs, even for hyperpolarizations that occur near phys- 
A

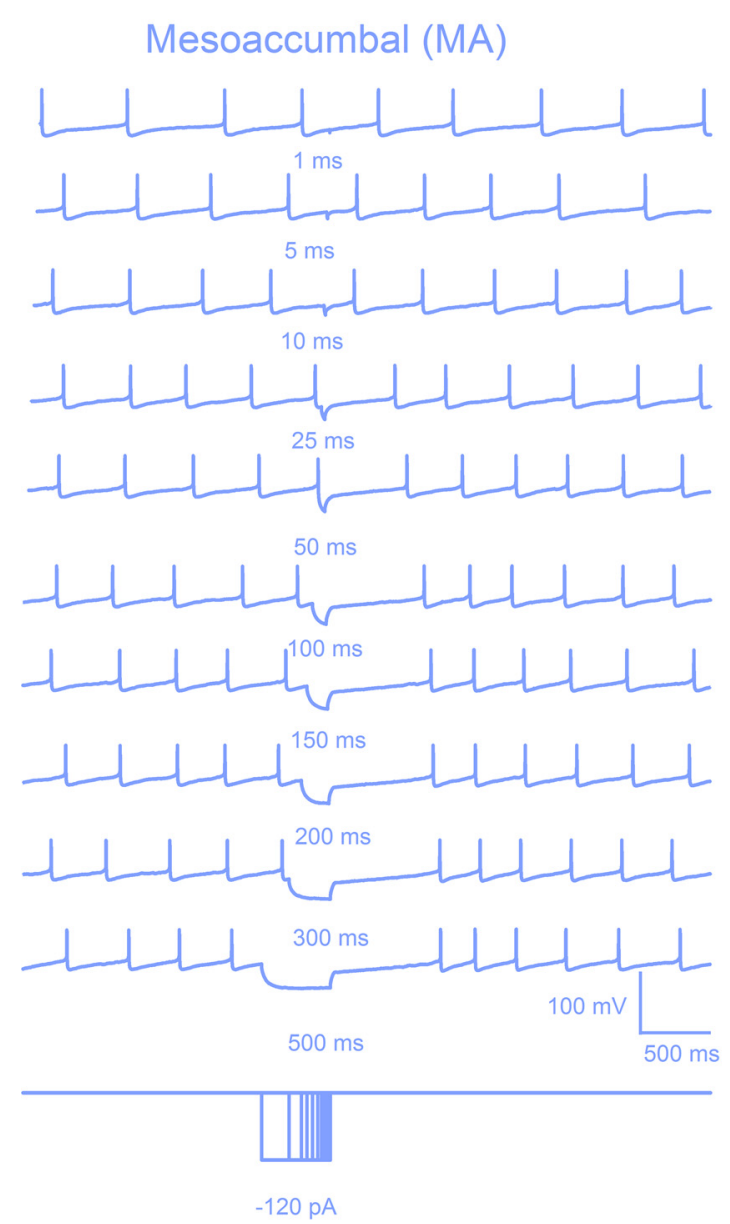

C

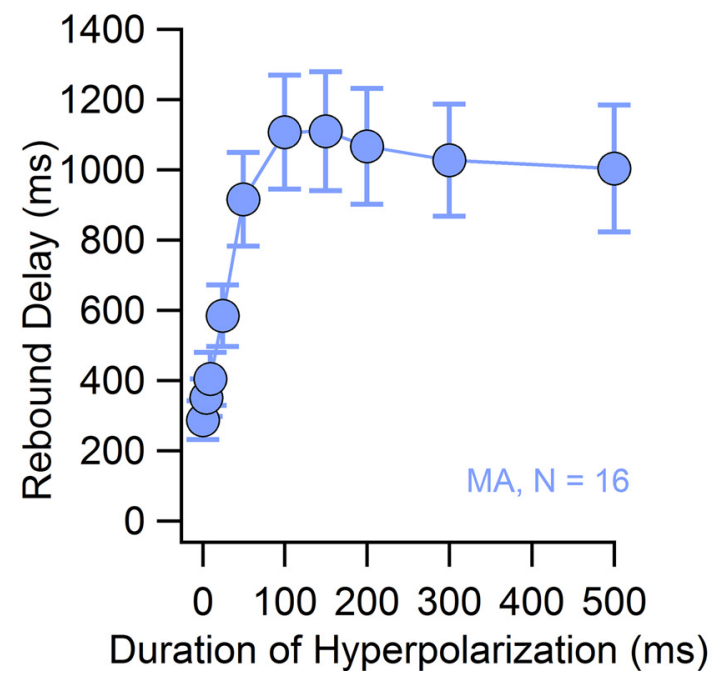

B

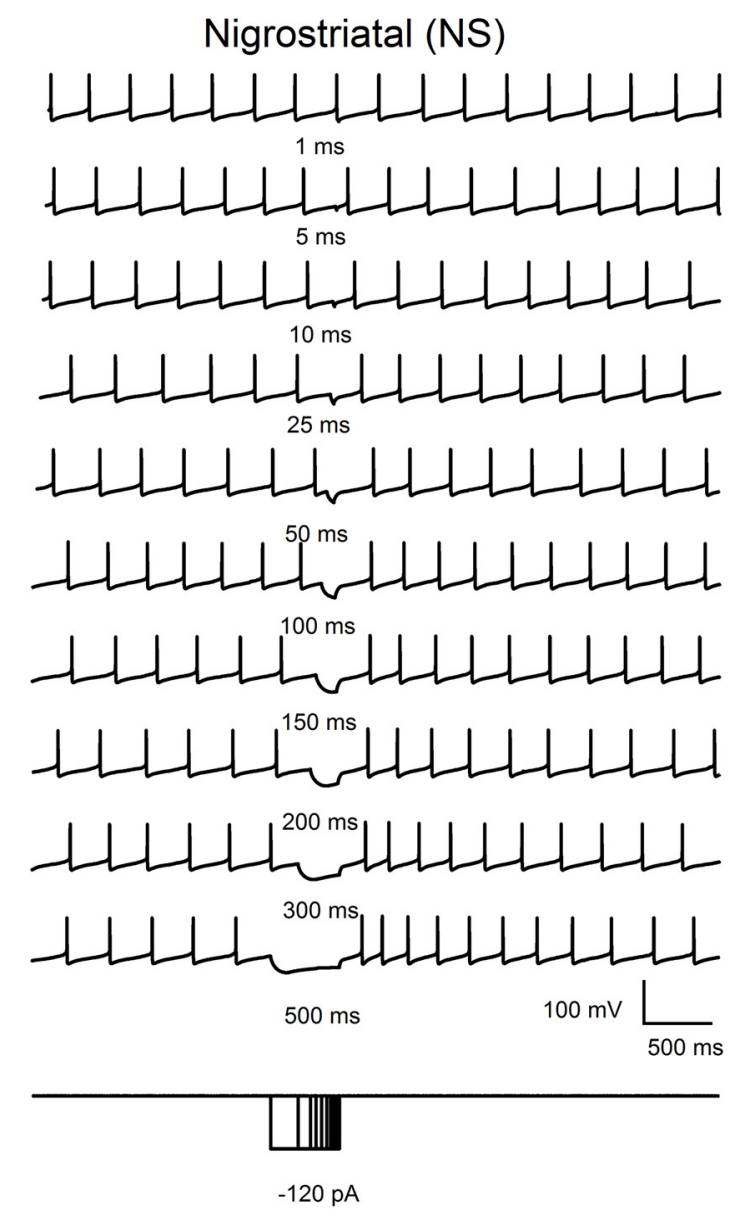

D

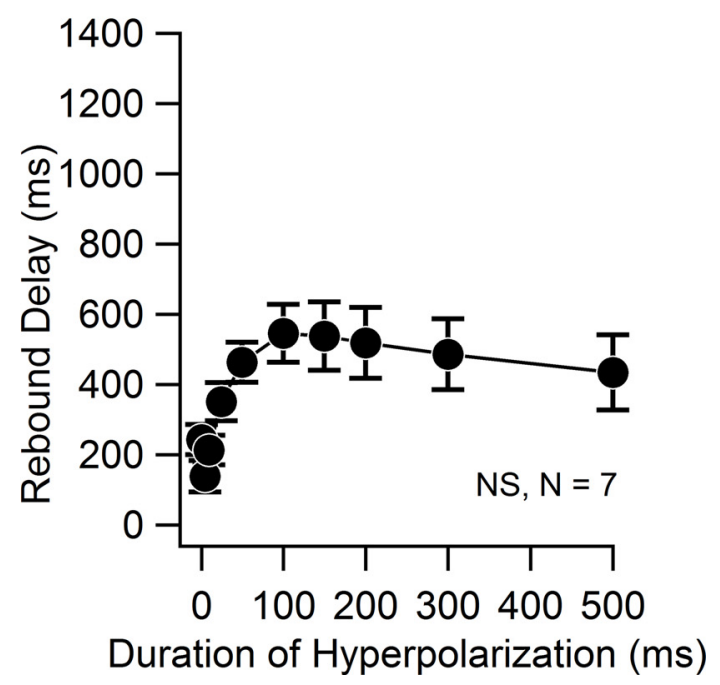

Figure 3. Time-dependent development of the rebound delay. $A$, Example of rebound pauses in a mesoaccumbal neuron in response to $120 \mathrm{pA}$ hyperpolarizing current injection delivered for different durations. $\boldsymbol{B}$, Same as in $\boldsymbol{A}$ for an example nigrostriatal neuron. $\boldsymbol{C}, \boldsymbol{D}$, Summary plots of rebound delays versus the duration of hyperpolarization in mesoaccumbal neurons (light blue symbols) and nigrostriatal neurons (black symbols). Data are plotted as averages \pm SEM.

iological voltages that are reached during natural pacemaker firing.

To rule out the possibility that these subpopulation specific responses may be attributed to differences in passive properties, we calculated the resistance in each neuron that resulted from the current amplitude injected in both mesoaccumbal and nigrostriatal dopamine neurons (Figs. 4G-I). Current injections that occurred only during the middle $50 \%$ of the interspike interval were 

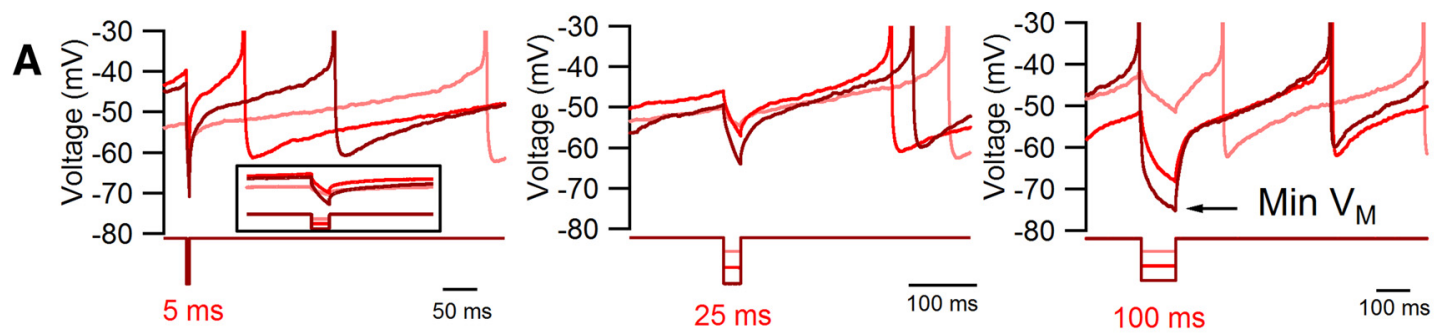

B
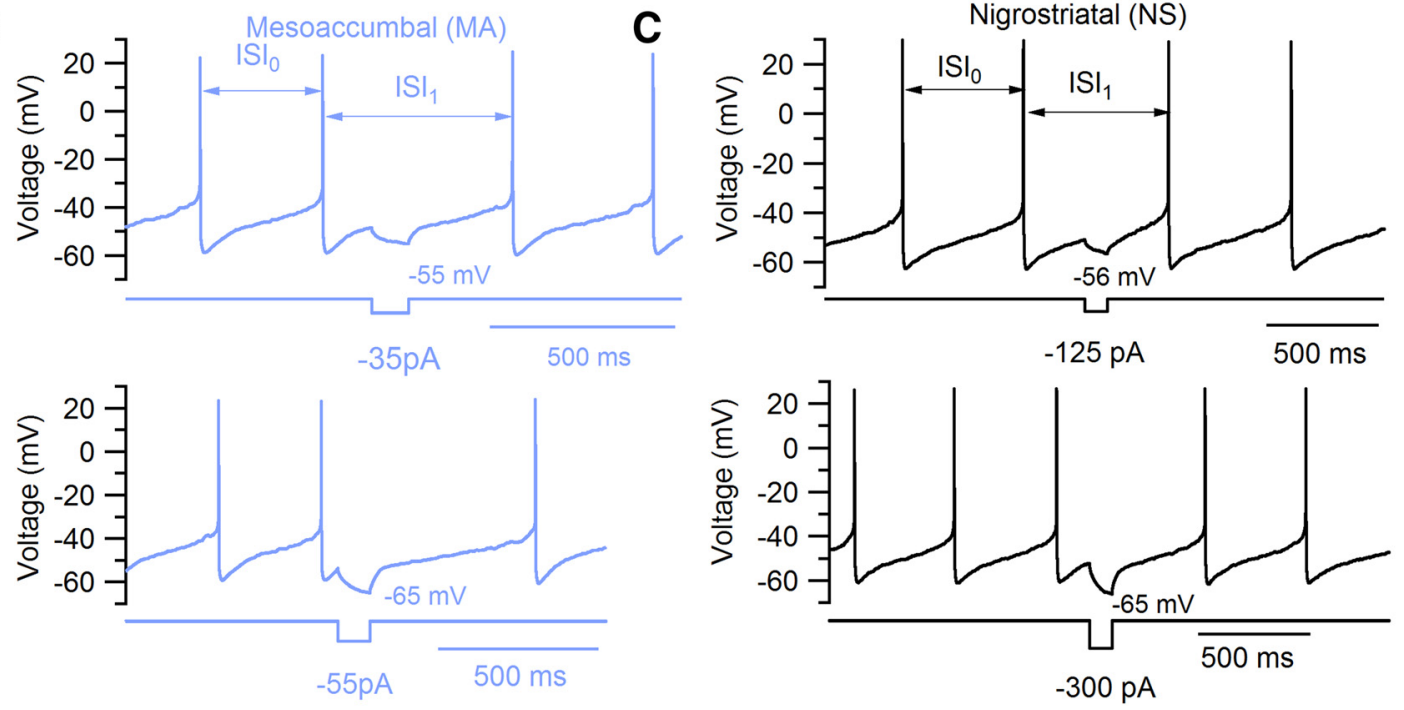

D

E
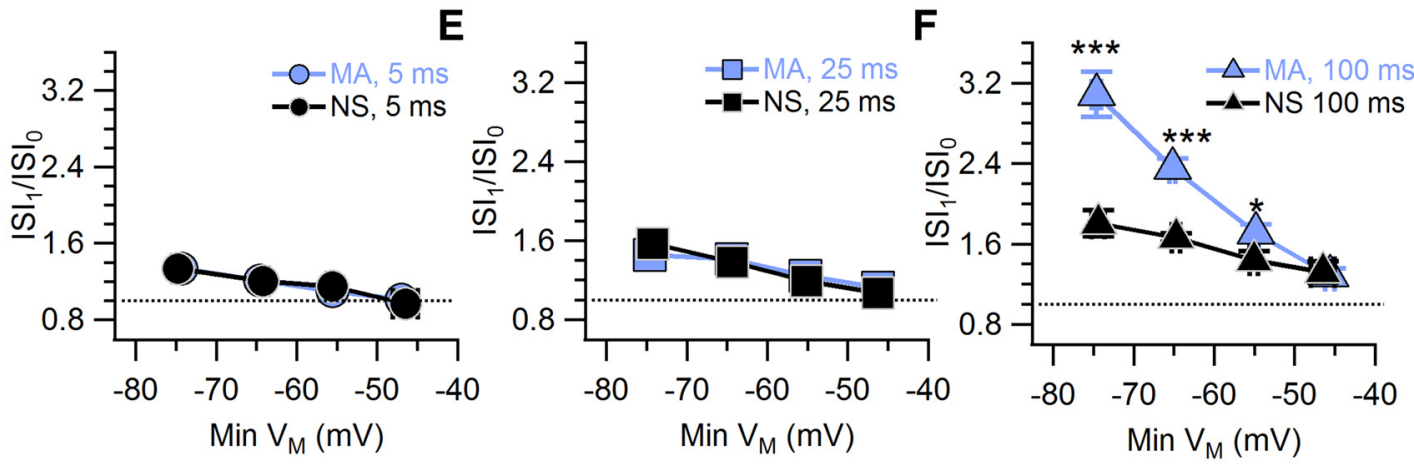

G

H
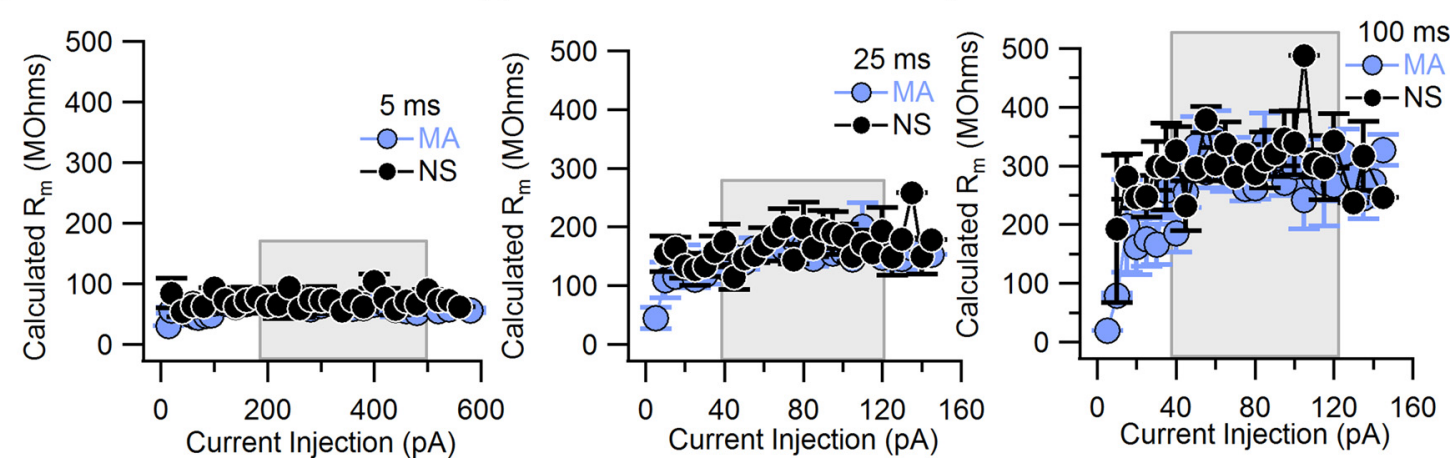

Figure 4. Effect of short duration hyperpolarizations in mesoaccumbal and nigrostriatal dopamine neurons. $\boldsymbol{A}$, Example traces from a single mesoaccumbal dopamine neurons in which spontaneous firing was interrupted for 5 ms by a family of 20 pA current injection steps (left). The inset shows a zoomed in image of the 5 ms hyperpolarization. Center, Same example neuron to the left, depicting the 25 ms hyperpolarization, carried out in 5 pA steps. Right, Same example neuron depicting the 100 ms hyperpolarization done in 5 pA steps. All neurons were injected with a series of current injection steps for 5, 25, and $100 \mathrm{~ms}$ in the aforementioned current injection amplitudes, interleaved with the neuron's spontaneous firing. $\boldsymbol{B}$, Example traces from a single mesoaccumbal dopamine neuron in which spontaneous firing was interrupted by separate $100 \mathrm{~ms}$ current injections. Top trace, $A-35$ pA injection hyperpolarized the membrane potential to a baseline voltage of $-55 \mathrm{mV}$, resulting in an $\mathrm{ISI}_{1}$ of $512.24 \mathrm{~ms}$ compared to an $\mathrm{ISI}_{0}$ of $330.4 \mathrm{~ms}$. Bottom trace, $\mathrm{A}-55 \mathrm{pA}$ injection hyperpolarized the membrane potential to a baseline voltage of $-65 \mathrm{mV}$, resulting in an $\mathrm{ISI}_{1}$ of $668.94 \mathrm{~ms}$ compared to an $\mathrm{ISI}_{0}$ of $320.66 \mathrm{~ms}$. C, Same as in $\boldsymbol{A}$ for an example nigrostriatal dopamine neuron. Spontaneous firing was interrupted by a $-125 \mathrm{pA}$ (top) and a $-300 \mathrm{pA}$ (bottom) current injection, which hyperpolarized the cell to a baseline voltage of $-56 \mathrm{mV}$ and $-65 \mathrm{mV}$. In the top trace, ISI ${ }_{1}=647.88 \mathrm{~ms}$ and ISI $=540.06 \mathrm{~ms}$. In the bottom trace, ISI $=663.12$ $\mathrm{ms}$ and $\mathrm{ISI}_{0}=457.70 \mathrm{~ms}$. $\boldsymbol{D}-\boldsymbol{F}$, Voltage dependence of the $\mathrm{ISI}_{1} / \mathrm{ISI}_{0}$ ratio in response to $5 \mathrm{~ms}(\boldsymbol{D}), 25 \mathrm{~ms}(\boldsymbol{E})$, and 100 ms $(\boldsymbol{F})$ hyperpolarizations in mesoaccumbal (light (Figure legend continues.) 
used to calculate the resistance. To compare input resistance between mesoaccumbal and nigrostriatal cells, we averaged calculated resistance values over a range of current steps for which the resistance values reached steady state (Fig. $4 G-I$, gray bars; $5 \mathrm{~ms}$ steps, 200-500 pA; 25 and 100 ms steps, 40-120 pA). Comparing the averaged resistance calculated at steady state for each neuron, we found that there was no significant difference between mesoaccumbal and nigrostriatal neurons in the resistance values for steps of $5 \mathrm{~ms}(p=0.49), 25 \mathrm{~ms}(p=0.70)$, and $100 \mathrm{~ms}(p=0.50)$. This confirms that the differences in spike-to-spike latency that we observed between mesoaccumbal and nigrostriatal neurons are not due to differences in passive membrane properties.

\section{Hyperpolarization-evoked spiking delays are lengthened by a} subclass of subthreshold potassium current $\left(\mathrm{I}_{\mathrm{A}}\right)$

Previous studies have shown that A-type potassium currents comprise the dominant subthreshold outward current in dopamine neurons, constraining the rate of spontaneous firing in VTA (Koyama and Appel, 2006; Khaliq and Bean, 2008) and SNc dopamine neurons (Liss et al., 2001). In addition, A-type potassium currents are known to contribute to the duration of the rebound delay in SNc cells (Amendola et al., 2012). We next tested the relationship between the interspike voltage trajectory and rebound delay within cells in mesoaccumbal and nigrostriatal subpopulations (Fig. 5A,B). Plotting the interspike voltage slope against the rebound delay, we found that the interspike slope shows a moderate to strong negative correlation with the duration of the rebound delay in both the mesoaccumbal neurons $(\operatorname{Pr}=-0.64, n=20, p=0.0024)$ and nigrostriatal neurons $(\mathrm{Pr}=$ $-0.62, n=28$, p-value $=0.00043$ ) (Fig. $5 C, D$ ). This demonstrates that despite the large cell-to-cell variability that exists within the data sets from each subpopulation, a clear relationship exists between the duration of the rebound delay and the voltage trajectory of the interspike spike interval in spontaneously firing dopamine neurons.

We next tested the contribution of A-type potassium currents to the interspike voltage trajectory of mesoaccumbal and nigrostriatal neurons using the specific A-type potassium channel blocker, AmmTX3 (Vacher et al., 2002). Bath application of 0.5-1 $\mu \mathrm{M}$ AmmTX3 resulted in a speeding of rate of spontaneous firing by $54 \%$ (control, $3.0 \pm 0.2 \mathrm{~Hz}$; AmmTX3, $4.7 \pm 0.3, n=$ 10 ) in mesoaccumbal neurons, and by $76 \%$ (control, $2.8 \pm 0.4$ $\mathrm{Hz}$; AmmTX3, $4.9 \pm 0.5, n=5$ ) in nigrostriatal neurons. In addition, we compared the voltage trajectory of the interspike intervals. On average, we found a significant increase in the slopes of the interspike interval in response to AmmTX3 in mesoaccumbal (control, $38.7 \pm 4.0 \mathrm{mV} / \mathrm{s}$; AmmTX3, $65.3 \pm 8.7 \mathrm{mV} / \mathrm{s} ; n=$ 10) and nigrostriatal neurons (control, $39.0 \pm 7.0 \mathrm{mV} / \mathrm{s} ; \mathrm{Am}-$ $\operatorname{mTX} 3,98.4 \pm 10.4 \mathrm{mV} / \mathrm{s} ; n=5$; $p=0.0015$; Fig. $5 E, F)$. Supporting previous findings (Khaliq and Bean, 2008), therefore, our results are consistent with the idea that A-type potassium currents control pacemaking by dynamically controlling the rate of spontaneous depolarization during the interspike interval.

We next tested the contribution of A-type potassium currents to rebound delays in the mesoaccumbal and nigrostriatal dopa-

$\leftarrow$

(Figure legend continued.) blue symbols) and nigrostriatal (black symbols) subpopulations. Asterisks indicate that mesoaccumbal and nigrostriatal cells display significant differences in delay responses to $100 \mathrm{~ms}$ hyperpolarizations starting at baseline values of $-55 \mathrm{mV}$. G-I, Plots of the average calculated resistance versus the current injection amplitude across all neurons within the mesoaccumbal (light blue symbols) and nigrostriatal (black symbols) subpopulations for $5 \mathrm{~ms}(\boldsymbol{G}), 25 \mathrm{~ms}(\boldsymbol{H})$, and $100 \mathrm{~ms}(\boldsymbol{I})$ hyperpolarizations. mine neuron subpopulations (Fig. 5G,H). We found that bathapplied AmmTX3 dramatically reduced the duration of rebound delays to only a fraction of the control duration in both mesoaccumbal (percentage control in AmmTX3, 79\%; $n=9 ; p=0.001$; Fig. $5 I$ ) and in nigrostriatal neurons (percentage control, 83\%; $n=6 ; p=0.01$; Fig. $5 J)$. Altogether, these data provide a clear demonstration that the variability in rebound delays that we observe across mesoaccumbal and nigrostriatal dopamine neuron subpopulations correlates strongly with subthreshold voltage trajectory, suggesting that $\mathrm{I}_{\mathrm{A}}$ is the common link between rebound delay and interspike voltage trajectory.

\section{GABA-evoked pauses are prolonged by recruitment of A-type} potassium currents

Our results so far strongly suggest that A-type potassium currents prolong the duration of spiking delays following somatic current injections but do not directly address their role in synaptically evoked inhibitory pauses. Therefore, we tested the effect of AmmTX3 on GABAergic pauses evoked by $50 \mathrm{~Hz}$ stimulation of inhibitory inputs for $300 \mathrm{~ms}$. To isolate GABAergic inputs, we included in the bath solution $50 \mu \mathrm{M}$ D-AP5 and $20 \mu \mathrm{M}$ CNQX to block NMDA and AMPA receptors along with the nonspecific mGluR antagonist $1 \mu \mathrm{M}$ LY341495 and $1 \mu \mathrm{M}$ sulpiride to block dopamine $\left(\mathrm{D}_{2}\right)$ autoreceptors. Following a $10 \mathrm{~min}$ baseline period, we found that bath application of AmmTX3 resulted in a $56 \%$ reduction of the averaged pause, from $1783 \pm 44 \mathrm{~ms}$ in control to $789 \pm 16 \mathrm{~ms}$ in AmmTX3 ( $n=6$; Fig. 6A,B). To verify that the stimulation-evoked pause was synaptic in nature and not due to direct stimulation, we blocked $\mathrm{GABA}_{\mathrm{A}}$ and $\mathrm{GABA}_{\mathrm{B}}$ receptors using $100 \mu \mathrm{m}$ picrotoxin and $1 \mathrm{~mm}$ CGP55845. This manipulation completely abolished the pause, as shown in Figure $5 \mathrm{~A}$ (blue trace).

In an analogous set of experiments, we evoked pauses in dopamine neurons by shining blue light to uncage RuBi-GABA ( 40 $\mu \mathrm{m}$ ) applied to the circulating bath solutions. Similarly, we found that GABA uncaging-evoked pauses were significantly shortened by $42 \%$ in the presence of AmmTX3, from $1995 \pm 120 \mathrm{~ms}$ in control to $1164 \pm 83 \mathrm{~ms}$ in $\operatorname{AmmTX} 3$ ( $n=6$; Fig. $6 C, D)$. These uncaging experiments support our above findings examining synaptically generated pauses and rule out the possibility that the effect of AmmTX3 could be presynaptic. Therefore, these results demonstrate that A-type potassium currents are recruited during active inhibitory neurotransmission and likely prolong the duration of GABAergic pauses.

Comparison of inactivation kinetics, voltage dependence, and recovery of A-type potassium currents in mesoaccumbal and nigrostriatal neurons

To better understand the ionic basis of the differences observed in the rebound delay between mesoaccumbal and nigrostriatal subpopulations, we performed voltage-clamp experiments to test the biophysical properties of the A-type potassium currents. To isolate A-type potassium currents, we recorded in a cocktail of blockers that included $1 \mu \mathrm{M}$ TTX, $30 \mu \mathrm{M}$ nifedipine, and $50 \mathrm{~mm}$ TEA-Cl to block voltage-gated sodium currents, low-threshold L-type Ca2 + currents, and high-threshold potassium currents.

We first measured the kinetics and voltage dependence of inactivation of isolated A-type potassium currents. Currents were evoked by steps from -90 to $-40 \mathrm{mV}$. A-type potassium currents in both mesoaccumbal and nigrostriatal neuron subpopulations were by far the largest amplitude currents that were present in the dopamine neurons (Liss et al., 2001; Khaliq and Bean, 2008; Amendola et al., 2012; Figs. 7 A, B). The amplitude of 
A

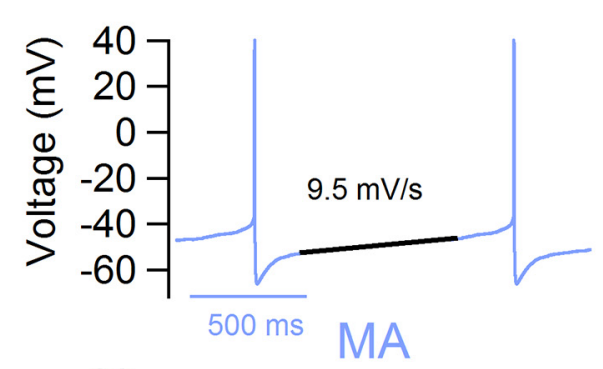

C

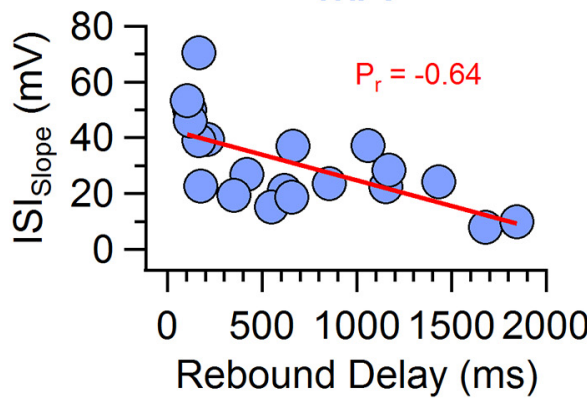

E

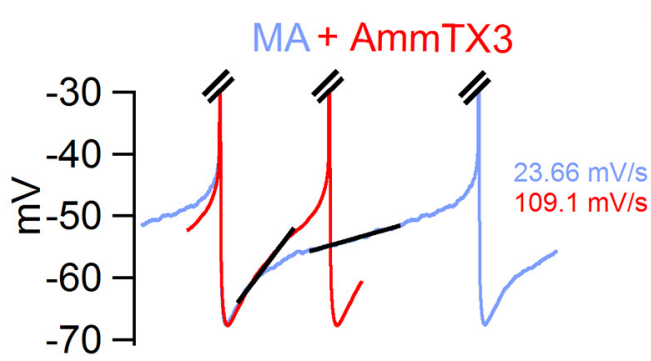

G
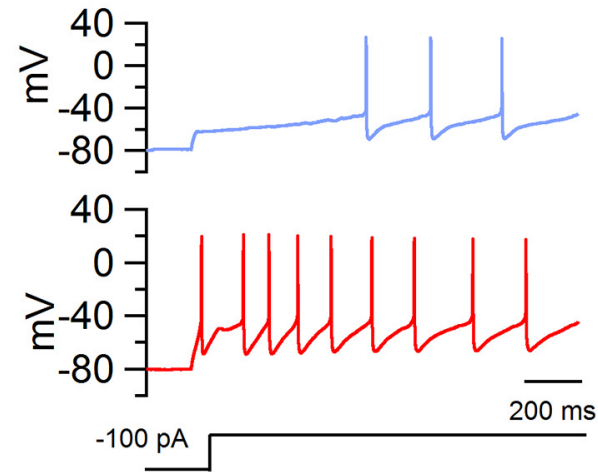

I

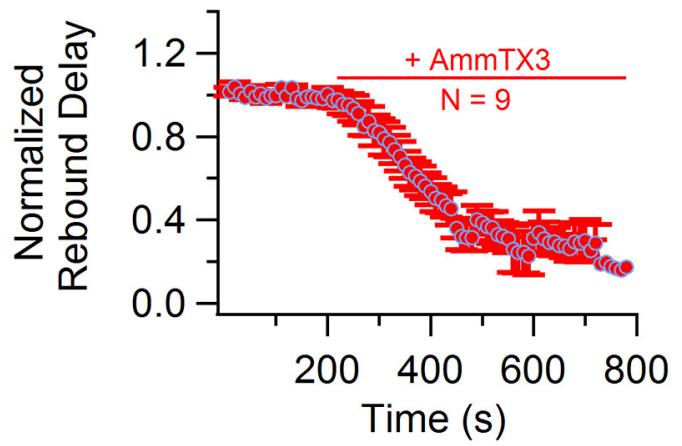

B

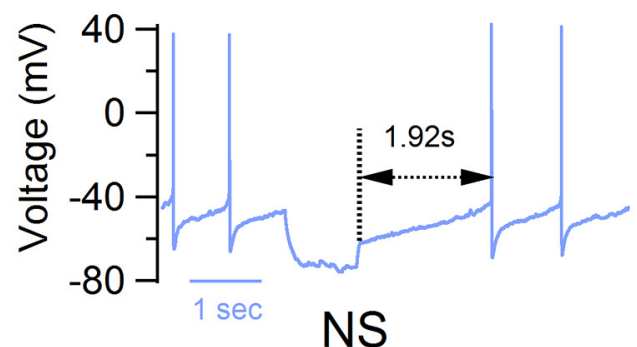

D

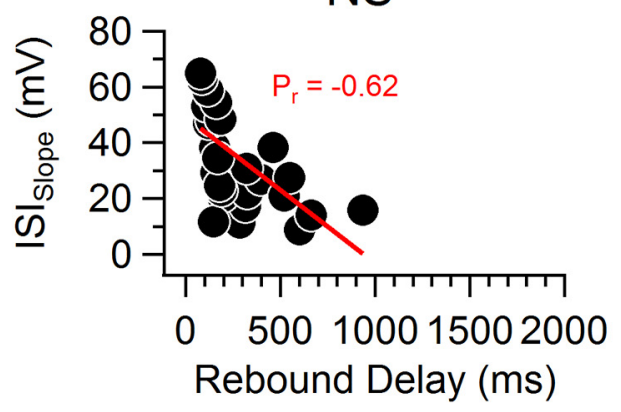

F

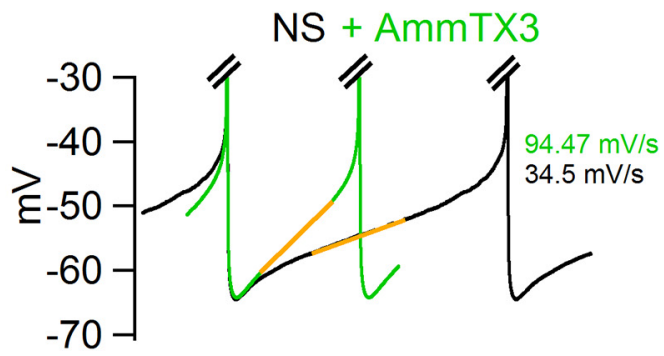

H
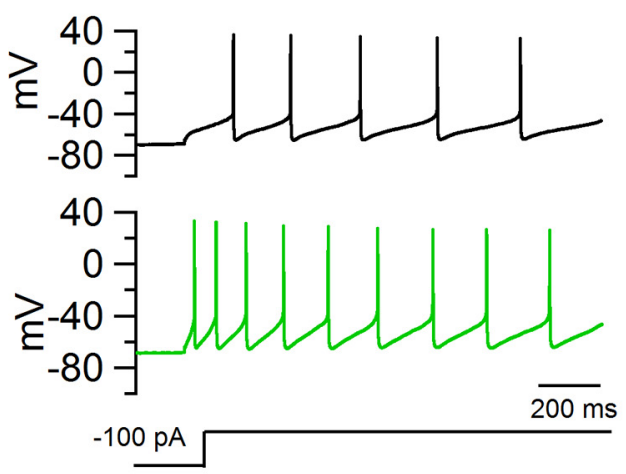

J

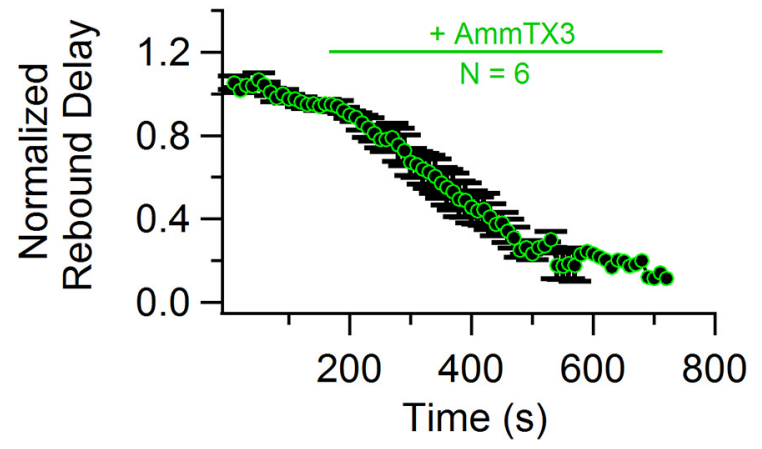

Figure 5. AmmTX3, a specific blocker of $\mathrm{K}_{\mathrm{v}} 4$ subunits, abolishes rebound pauses of all durations in mesoaccumbal and nigrostriatal dopamine neurons. $\boldsymbol{A}$, Example of an averaged interspike interval from a spontaneously active mesoaccumbal dopamine neuron. The black line indicates linear fit to slope. $\boldsymbol{B}$, Rebound delay from the same neuron. $\boldsymbol{C}, \boldsymbol{D}$, Plot of the relationship between the slope of the interspike voltage trajectory and the rebound delay. $\boldsymbol{E}$, Example traces from a mesoaccumbal neuron demonstrating effect of 1M AmmTX3 on interspike voltage trajectory during pacemaking. The interspike interval slope increased from 23.66 to $109.1 \mathrm{mV} / \mathrm{s}$ in the presence of $1 \mathrm{M}$ of AmmTX3. $\boldsymbol{F}$, Effect of AmmTX3 on interspike voltage trajectory of a nigrostriatal neuron. The interspike voltage increased from 34.5 to $94.47 \mathrm{mV} / \mathrm{s}$ in AmmTX3. G, $\boldsymbol{H}$, Traces demonstrating effect of AmmTX3 in reducing rebound pause in mesoaccumbal $(\boldsymbol{E})$ and nigrostriatal $(\boldsymbol{F})$ dopamine neurons. $\boldsymbol{I}, \boldsymbol{J}$, Averaged time course of normalized rebound delays under control conditions and following application of 1M AmmTX3 in mesoaccumbal (orange symbols; $\boldsymbol{I}$ ) and nigrostriatal dopamine neurons (black symbols; J). Data are shown as averages \pm SEM. 


\section{A Stimulation}
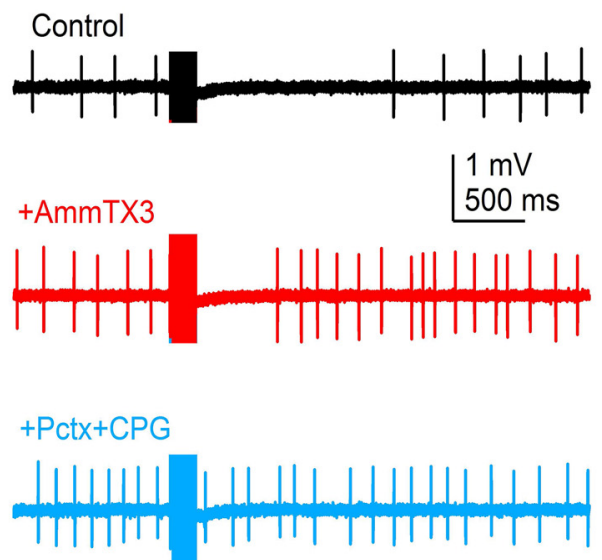

III $50 \mathrm{~Hz}$ stim

\section{Rubi-GABA Uncaging}
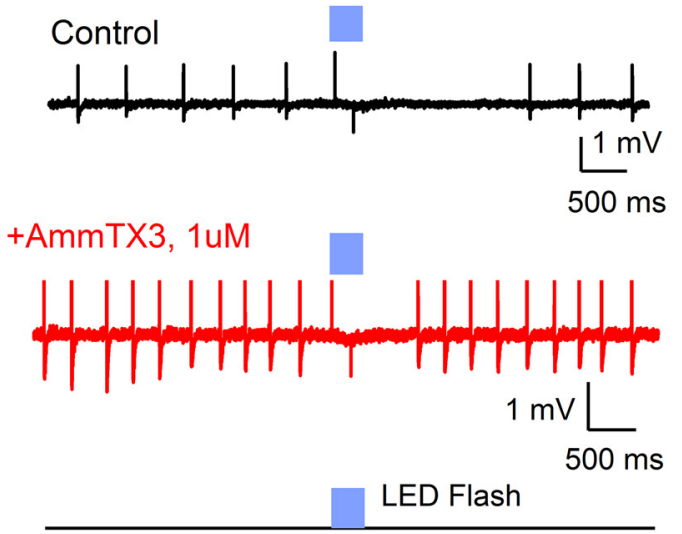

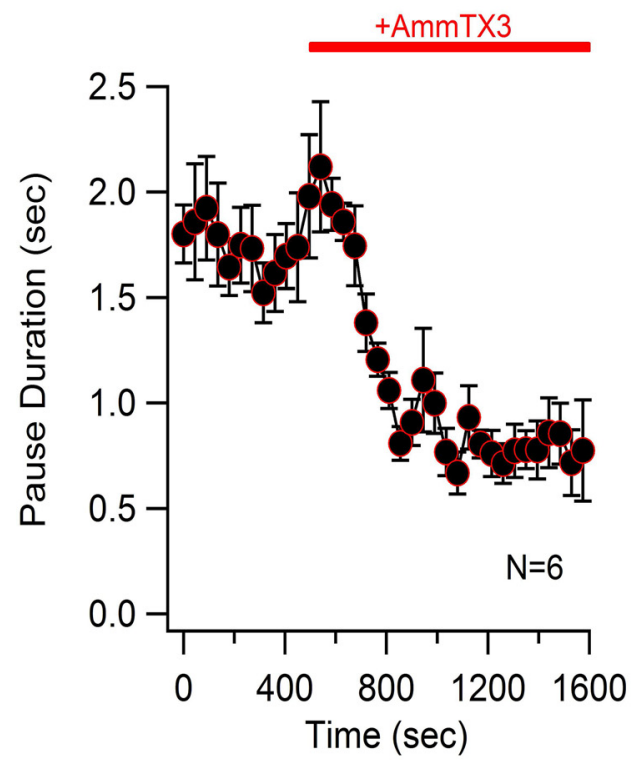

D

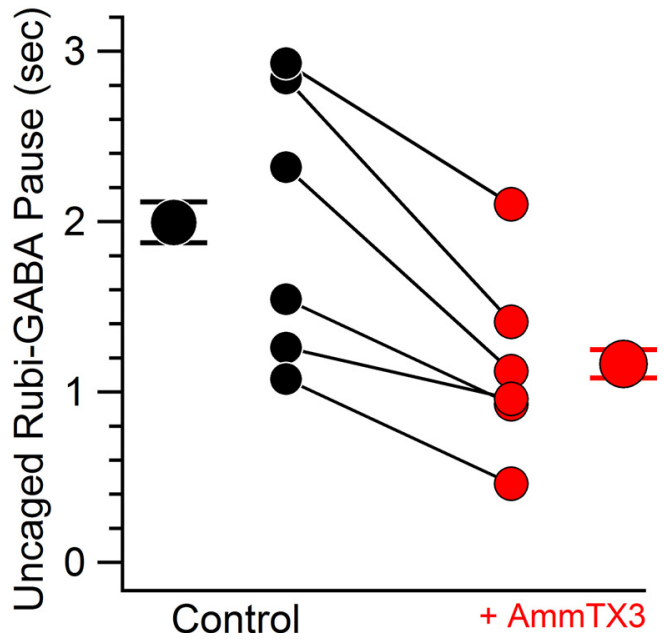

Figure 6. Pauses evoked by inhibitory synaptic stimulation and GABA uncaging reduced by AmmTX3 block of A-type potassium currents. $A$, Effect of AmmTX3 on synaptically evoked pauses. Cell-attached recording of a pause in a VTA neuron evoked by $50 \mathrm{~Hz}$ stimulation for $300 \mathrm{~ms}$ under control conditions (black trace), in AmmTX3 (red trace), and in the presence of picrotoxin and CGP55845 (blue trace). Spikes are cropped. B, Averaged time course of inhibitory pause under control conditions and following bath application of AmmTX3 for 6 VTA neurons. C, Effect of AmmTX3 on inhibitory pauses evoked by RuBi-GABA uncaging. Cell-attached recording of a pause under control conditions (black trace) in AmmTX3 (red trace). Spikes are cropped. D, Summary plot of the effect of AmmTX3 block on uncaging-evoked pause in six VTA neurons.

$\mathrm{I}_{\mathrm{A}}$ measured from steps to $-40 \mathrm{mV}$ did not differ significantly between subpopulations (mesoaccumbal, $1.65 \pm 0.32 \mathrm{nA}, n=$ 22; nigrostriatal, $1.3 \pm 0.15 \mathrm{nA}, n=18$; Mann-Whitney test, $p=$ $0.26)$. However, we observed a striking difference in the inactivation kinetics of the A-type currents between mesoaccumbal and nigrostriatal subpopulations (Fig. 7C,D). Specifically, A-type currents recorded in nigrostriatal neurons decayed with relatively fast time constants ranging from $13.5 \mathrm{~ms}$ to $68.9 \mathrm{~ms}$, and exhibited an average decay time constant of $36.2 \pm 3.3 \mathrm{~ms}(n=18$; Fig. $7 D$ ). By contrast, A-type currents measured in mesoaccumbal neurons displayed a much wider range of inactivation time constants from 14.5 to $224.3 \mathrm{~ms}$, with 11 of 22 cells exhibiting atypically slow inactivation kinetics with decay time constants longer than $100 \mathrm{~ms}$. On average, A-type currents in mesoaccumbal neurons had substantially slower decay time constants of $98.7 \pm 10.8$ ms $(n=22$; Fig. $7 D$; mesoaccumbal vs nigrostriatal, $p=3.4 \mathrm{e}-05$, Mann-Whitney test). As a point of comparison, A-type currents measured in outside-out patches from CA1 pyramidal cells decay much faster, with an average time constant of $26 \mathrm{~ms}$ (Kim et al., 2008). Therefore, we found that inactivation of A-type potassium currents in dopamine neurons occurs over a broad range of inactivation rates, but is unusually slow in mesoaccumbal neurons.

In the same set of cells, we compared the voltage dependence of inactivation. We determined the voltage dependence by plotting the peak current measured at $-40 \mathrm{mV}$ against the prepulse voltage and fit the data to the Boltzmann equation to obtain voltages of half-inactivation. Interestingly, we found that the voltage of half-inactivation of A-currents occurred at slightly more hyperpolarized potentials in mesoaccumbal neurons relative to nigrostriatal neurons. On average, half-inactivation voltage was $-66.6 \pm 1.4$ 

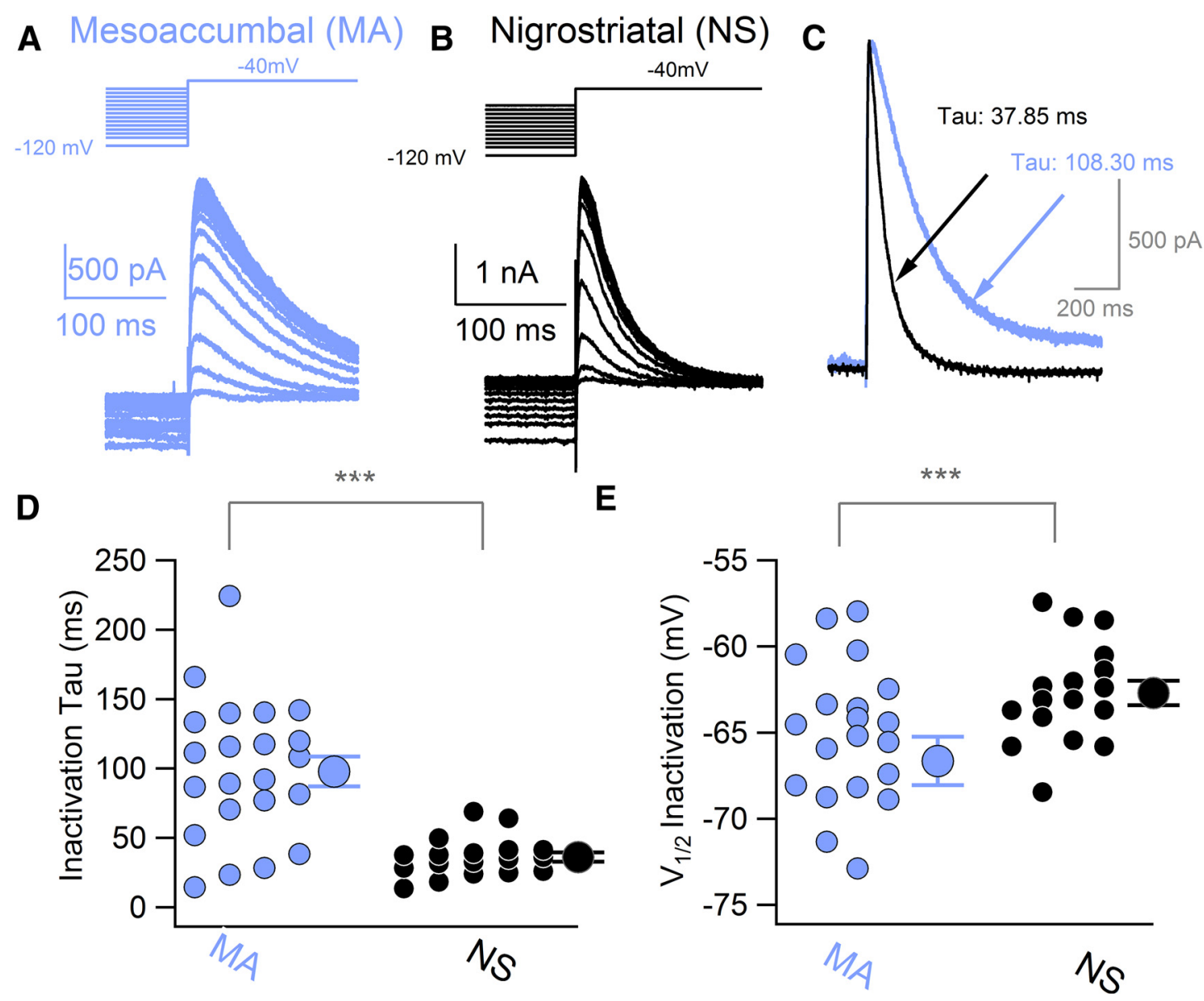

Figure 7. Biophysical properties of A-type potassium currents midbrain dopamine neurons. $A, B$, Voltage protocol (top) and example traces (bottom) of A-type potassium currents in mesoaccumbal (light blue traces; $\boldsymbol{A}$ ) and nigrostriatal (black traces; $\boldsymbol{B}$ ) dopamine neurons evoked by a family of voltage steps to $-40 \mathrm{mV}$ stepping from a range of voltages between -120 and $-50 \mathrm{mV}$. C, Comparison of inactivation kinetics of A-type potassium currents evoked by steps from -90 to $-40 \mathrm{mV}$. Inactivation time constants were determined from fits to single exponential functions. $\boldsymbol{D}$, Summary of inactivation voltage dependence of half inactivation in mesoaccumbal (light blue symbols) and nigrostriatal (black symbols) dopamine neurons. $\boldsymbol{E}$, Summary of inactivation time constant measured from steps to $-40 \mathrm{mV}$ in mesoaccumbal and nigrostriatal dopamine neurons. ${ }^{* * *}, P<0.05$.

$\mathrm{mV}$ (slope, $5.2 \pm 0.4 ; n=18$ ) in mesoaccumbal neurons but $-62.7 \pm 0.7 \mathrm{mV}$ (slope, $4.7 \pm 0.16 ; n=22$ ) in nigrostriatal neurons (mesoaccumbal vs nigrostriatal, $p=0.02$, Mann-Whitney $\mathrm{U}$; Fig. 7E).

It is possible that the range of kinetics observed in our recordings may result partly from inadequate space clamp. However, two pieces of evidence argue against this scenario. First, outside-out patch recordings from the dendrites and soma of SNc dopamine neurons indicate that the highest of density of $\mathrm{I}_{\mathrm{A}}$ channels is located in soma (Gentet and Williams, 2007). Second, dopamine neurons exhibit extraordinarily high input resistances of $0.3-1 \mathrm{G} \Omega$ for principal neurons and their dendrites display little branching, both of which result in strongly isopotential soma and proximal dendrites (Hausser et al., 1995; Khaliq and Bean, 2010; Hage and Khaliq, 2015).

The roughly exponential time course of the development of the rebound delay shown in Figure 2 hints strongly at a process that depends upon recovery from channel inactivation. Therefore, we compared recovery from inactivation of A-type currents recorded from mesoaccumbal and nigrostriatal dopamine neurons (Fig. 8). To test recovery from inactivation, we applied a $250 \mathrm{~ms}$ conditioning step to $-40 \mathrm{mV}$ to allow for nearly complete inactivation of $\mathrm{I}_{\mathrm{A}}$ that was then followed by a variable period of recovery at $-70 \mathrm{mV}$ (Fig. $8 A$ ). The extent of recovery was then assayed using a test pulse to $-40 \mathrm{mV}$. Plotting the peak of the test pulse versus the recovery time period, we found that these values fit well to a single exponential indicating that recovery occurs mainly from only a single inactivated state (Fig. $8 B$ ). In a population of cells (Fig. 8C), the time constant of recovery recorded in mesoaccumbal neurons ranged widely from 24.26 to $133.33 \mathrm{~ms}$, with an average of $64.51 \pm 12.84 \mathrm{~ms}(n=8)$. In nigrostriatal neurons, there was a trend toward a slightly quicker recovery from inactivation which ranged from 32.1 to $46.28 \mathrm{~ms}$, with an average of $36.92 \pm 1.86 \mathrm{~ms}(n=7)$. These values for recovery from inactivation in both cell types match approximately the values for development of the rebound delay shown in Figure 2, further suggesting that A-type currents contribute strongly to rebound delays. Therefore, we found that mesoaccumbal and nigrostriatal dopamine neurons, exhibited pronounced differences in the kinetics and voltage dependence, but not amplitudes, of their A-type potassium currents.

\section{Comparison of $\mathrm{IH}$ and sag potentials in mesoaccumbal and nigrostriatal neurons}

Because hyperpolarization-gated cation currents $\left(\mathrm{I}_{\mathrm{H}}\right)$ are known to reduce the duration of the rebound delay in midbrain dopamine neurons (Neuhoff et al., 2002; Amendola et al., 2012), we next asked whether differential expression of $\mathrm{I}_{\mathrm{H}}$ contributes to the differences in rebound delays observed between mesoaccumbal and nigrostriatal dopamine neurons. We directly recorded $\mathrm{I}_{\mathrm{H}}$ in voltage clamp with $1 \mathrm{~s}$ voltage steps 


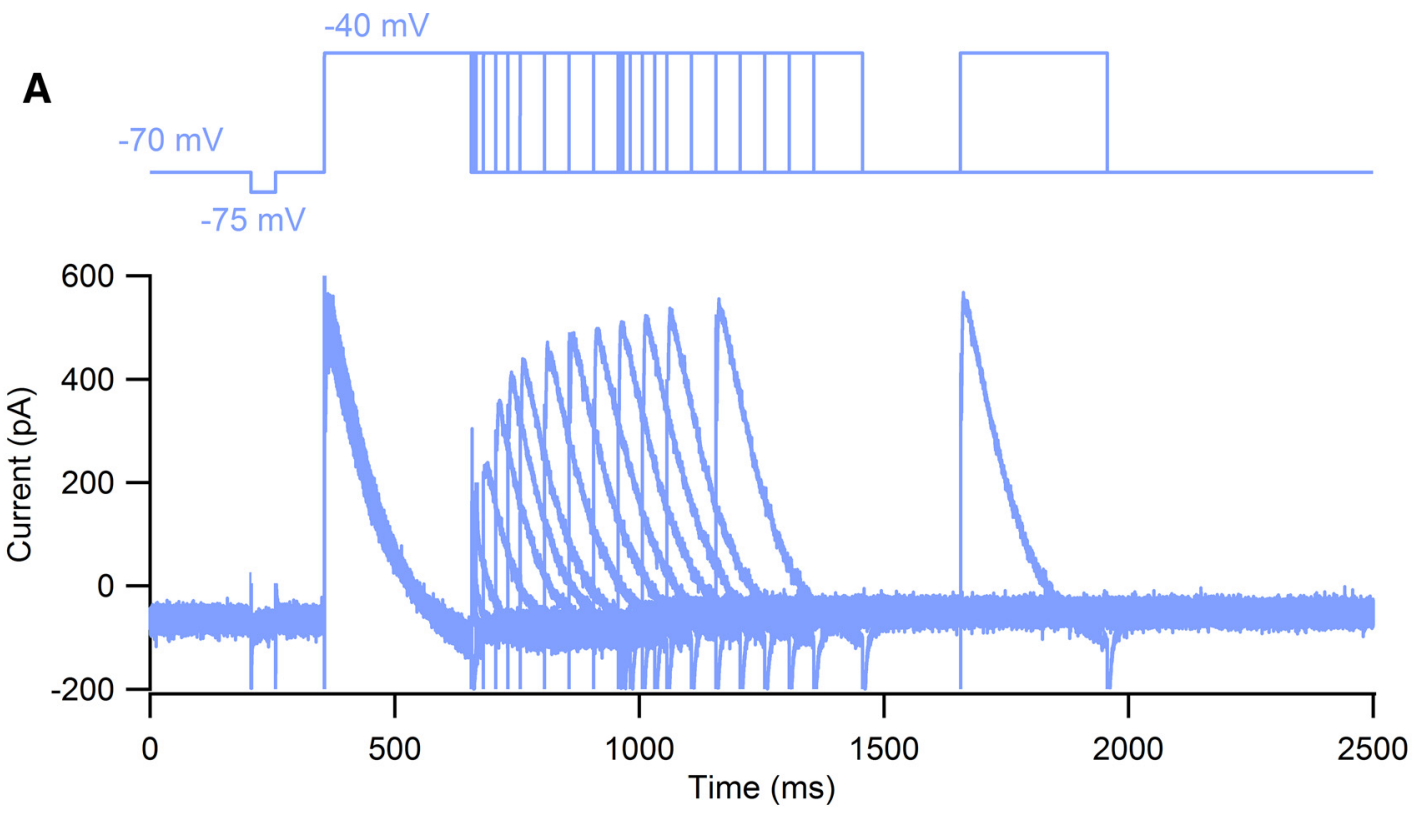

B

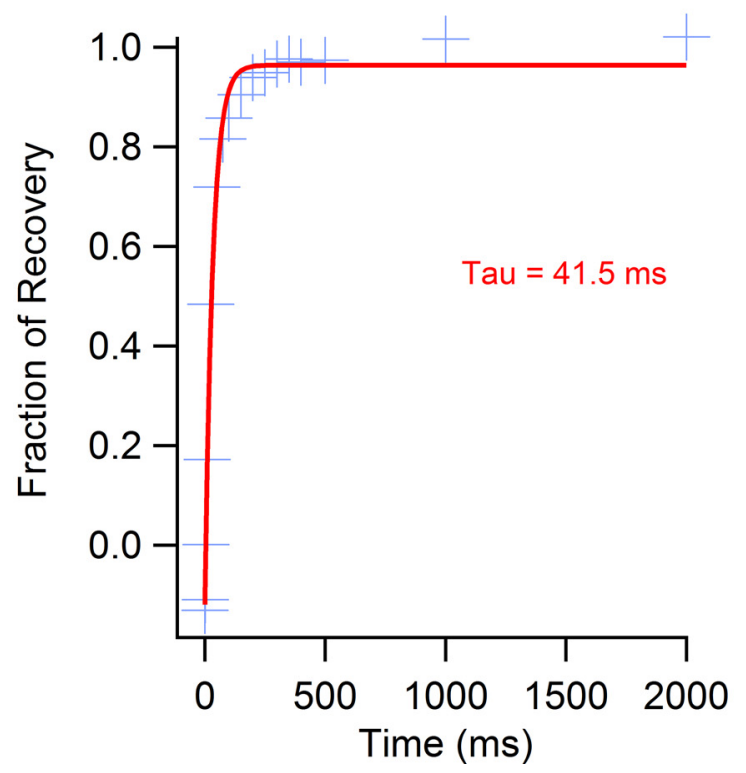

C

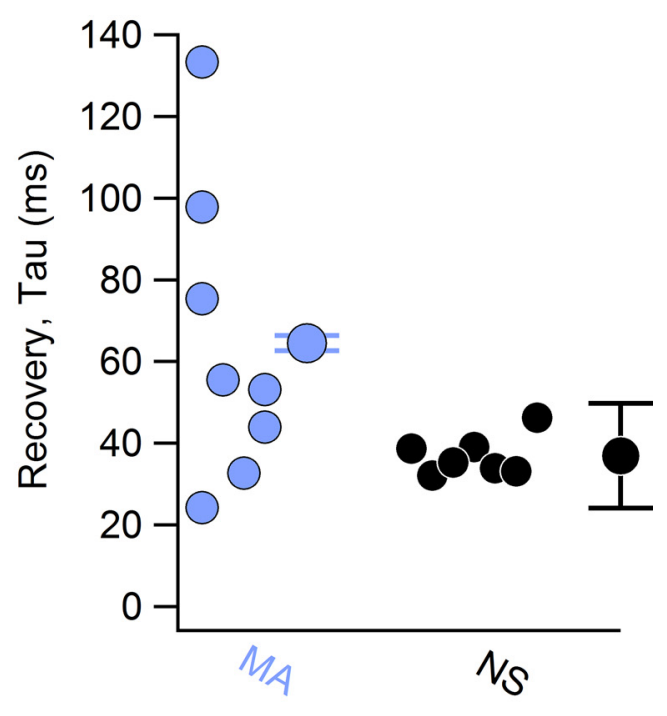

Figure 8. Recovery from inactivation of A-type potassium currents in mesoaccumbal and mesostriatal dopamine neurons. $A$, Voltage protocol (top) and example traces (bottom) testing recovery from inactivation following a $250 \mathrm{~ms}$ conditioning step from -70 to $-40 \mathrm{mV}$. Recovery was tested over a range of intervals including $1-2000 \mathrm{~ms}$. $\boldsymbol{B}$, Plot of fraction of recovery for data shown in $\boldsymbol{A}$. Current from test pulses were normalized to current evoked by conditioning pulse. Fit to a single exponential function is shown in red. C, Summary of recovery time constants for A-type currents recorded in mesoaccumbal and nigrostriatal neurons.

from $-40 \mathrm{mV}$ to a range of hyperpolarized voltages between -80 and $-120 \mathrm{mV}$ (Fig. 9A,B). On average, the amplitude of $\mathrm{I}_{\mathrm{H}}$ was significantly larger in the nigrostriatal compared to mesoaccumbal neurons (amplitude at $-120 \mathrm{mV}$, mesoaccumal, $-257.9 \pm 56.3 \mathrm{pA}, n=12$; nigrostriatal, $-577.3 \pm$ 50.7, $n=9 ; p=0.0033$; Fig. 9C). Quantifying the kinetics of $\mathrm{I}_{\mathrm{H}}$, however, we found that $\mathrm{I}_{\mathrm{H}}$ activation is slow. The activation time constant measured from steps to $-100 \mathrm{mV}$ was $\sim 1 \mathrm{~s}$, and we observed no significant differences in the average activation time constant for $\mathrm{I}_{\mathrm{H}}$ in mesoaccumbal and nigrostriatal dopamine neurons at any of the voltages that were tested (Fig. 9D).

Dopamine neurons respond to hyperpolarizing current injection with a characteristic depolarizing voltage sag due to activa- tion of $\mathrm{I}_{\mathrm{H}}$ (Fig. 9E,F). We next compared sag potentials in dopamine neuron subpopulations. To do this, we evoked voltage sags by injecting hyperpolarizing current and then quantified sag potentials by taking the voltage difference between the trough voltage and the steady baseline voltage at the end of the current step. Consistent with our voltage-clamp results described above, we observed that voltage sags were approximately twice as large in nigrostriatal neurons as measured in mesoaccumbal neurons (sag potential at baseline of $\sim-86 \mathrm{mV}$, mesoaccumbal, $14.1 \pm 2.05 \mathrm{mV}$, $n=28$; nigrostriatal, $29.3 \pm 3.04 \mathrm{mV}, n=36 ; p=0.00052$; Fig. 9G). Together, our results demonstrate the presence of larger amplitude $\mathrm{I}_{\mathrm{H}}$ and, accordingly, larger amplitude sags in the nigrostriatal subpopulation compared to the mesoaccumbal subpopulation. 
A

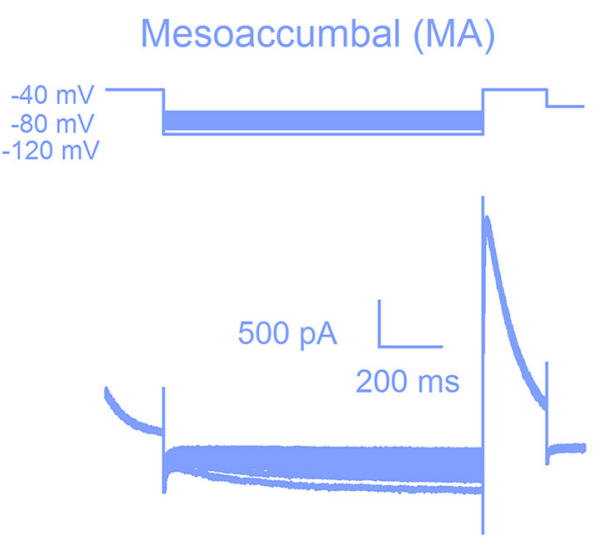

B
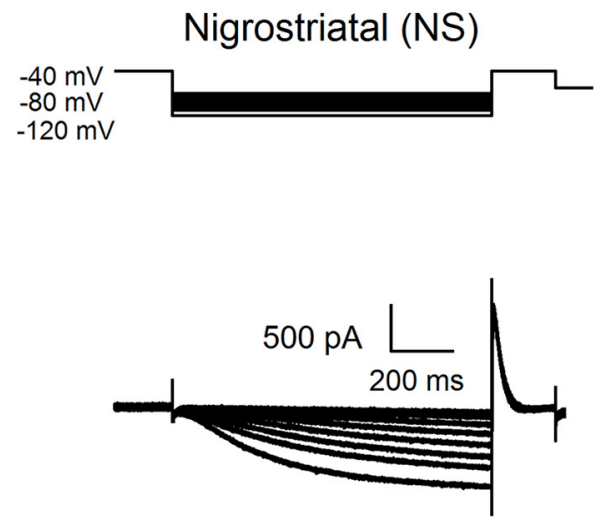

E

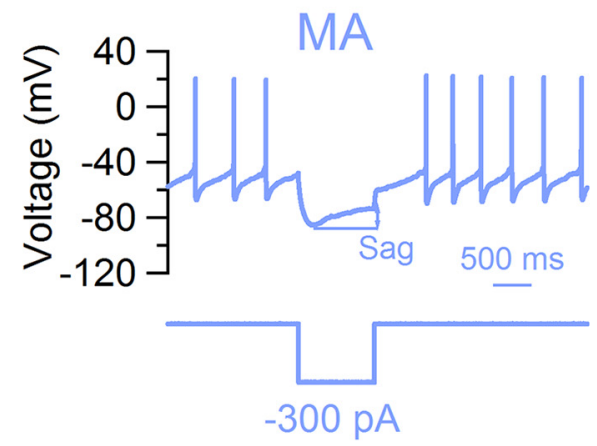

$\mathbf{F}$

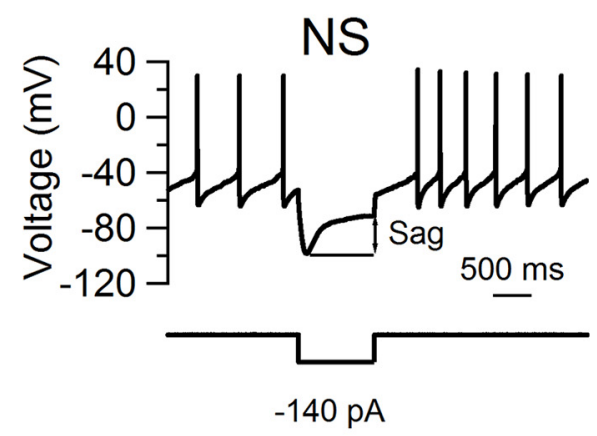

C

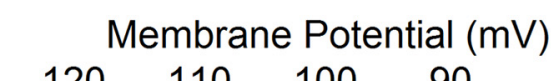

$\begin{array}{llll}-120 & -110 & -100 & -90\end{array}$

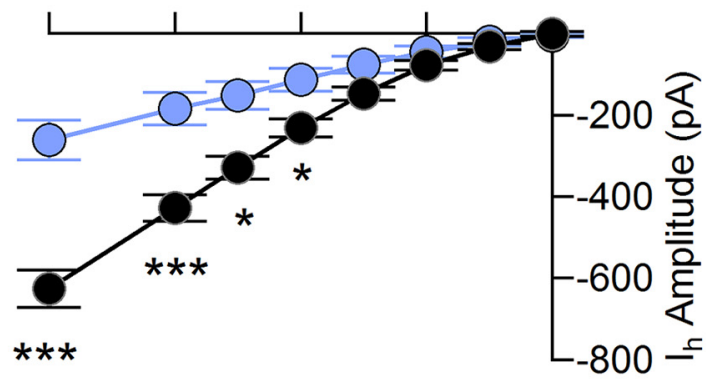

D

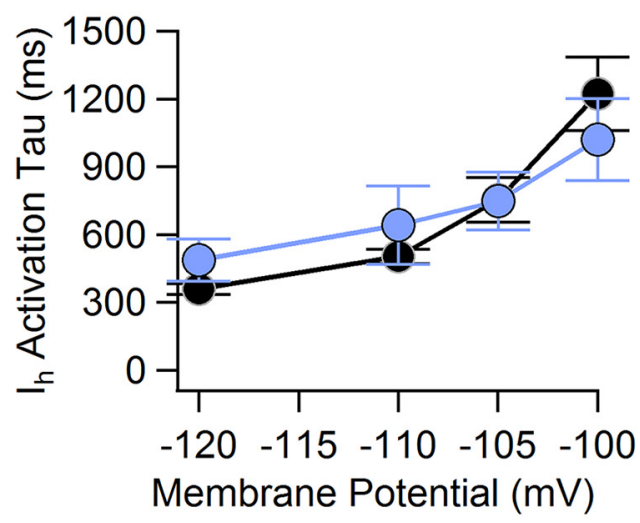

G

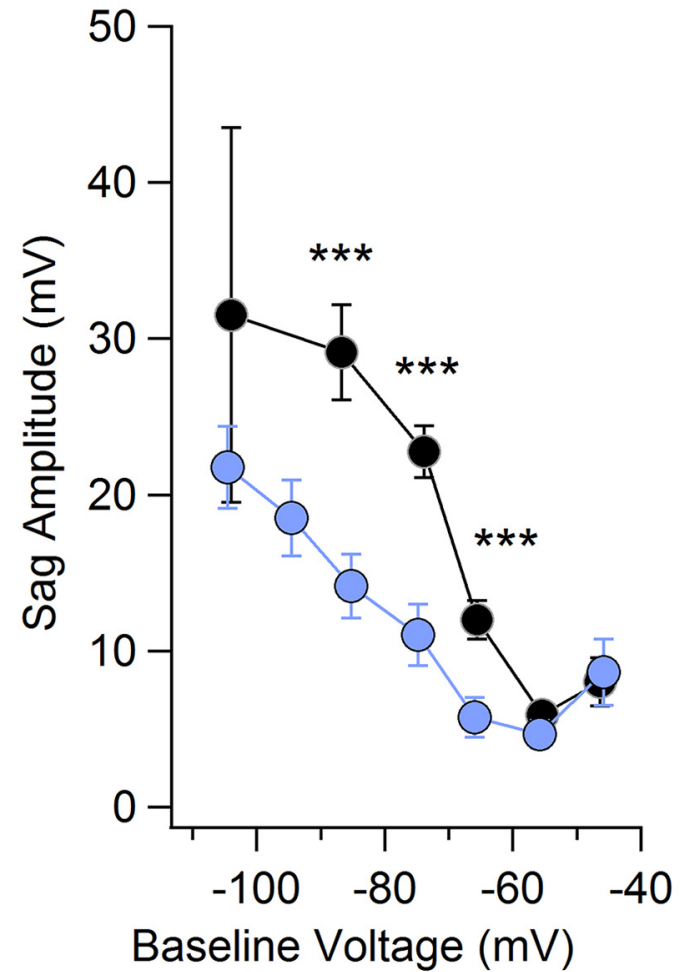

Figure 9. Biophysical properties of $\mathrm{H}$-current in mesoaccumbal and nigrostriatal subpopulations. $A, B$, Voltage protocols (top) and representative family of hyperpolarization-activated currents (IH; bottom) evoked by a range of steps from -120 to $-80 \mathrm{mV}$, recorded in a mesoaccumbal $(\boldsymbol{A})$ and nigrostriatal $(\boldsymbol{B})$ dopamine neurons. $\boldsymbol{C}$, Summary current-voltage relationship plots for $\mathrm{H}$ currents recorded from mesoaccumbal (light blue) and nigrostriatal (black) dopamine subpopulations. D, Summary of time constant of activation for $\mathrm{H}$ currents measured in mesoaccumbal and nigrostriatal dopamine subpopulations. Time constant of activation values were obtained by fitting an exponential to the raw current traces of $H$ currents. $\boldsymbol{E}, \boldsymbol{F}$, Example traces displaying depolarizing sag potentials in response to hyperpolarizing current injections in mesoaccumbal $(\boldsymbol{E})$ and nigrostriatal $(\boldsymbol{F})$ neurons. Sag potentials were measured as the difference between the peak minimum and baseline voltages. $\mathbf{G}$, Summary plot of sag amplitudes measured in mesoaccumbal and nigrostriatal dopamine neurons. ***, $P<0.05$. 


\section{Correlating A-type potassium current kinetics and $\mathrm{I}_{\mathrm{H}}$ amplitude to the duration of rebound delay in mesoaccumbal and nigrostriatal dopamine neurons}

Because mesoaccumbal and nigrostriatal dopamine subpopulations differ in the kinetics of A-type potassium currents and in the amplitude of $\mathrm{I}_{\mathrm{H}}$, we next asked how closely the differences in conductances correlate with the observed neuronal responses to hyperpolarization (Fig. 10A,B). First, plotting the rebound slope and against the inactivation kinetics of the A-type potassium currents (Fig. 10C), we found a strong negative correlation between rebound slope and the time constant of A-type current inactivation $(\operatorname{Pr}=-0.69, n=29, p=3.56 \mathrm{e}-0.5)$. We next compared values for rebound slope and the amplitude of the $\mathrm{I}_{\mathrm{H}}$ current and found that these values were positively correlated with a Pr value of 0.59 ( $p=0.0016$; Fig. $10 D)$. We also found a correlation between the amplitude of A-type current (at -40 $\mathrm{mV}$ ) and the amplitude of $\mathrm{IH}$ (at $-120 \mathrm{mV} ; \operatorname{Pr}=0.5, n=26$; $p=0.009$; Fig. $10 E$ ). By contrast, we found little to no correlation between the rebound slope and absolute amplitude of the A-type potassium current $(\mathrm{Pr}=-0.13$; Fig. $10 F)$. Therefore, our present data in the identified mesoaccumbal and nigrostriatal subpopulations shows that the kinetics of $\mathrm{I}_{\mathrm{A}}$ and the amplitude of $\mathrm{I}_{\mathrm{H}}$ correlates well with the duration of rebound delays in dopamine neurons.

\section{Testing the relative contribution of $\mathrm{I}_{\mathrm{A}}$ kinetics and $\mathrm{IH}$ amplitude to rebound delay in a computational dopamine neuron model}

To develop a better understanding of how differences in $\mathrm{I}_{\mathrm{A}}$ kinetics and $\mathrm{I}_{\mathrm{H}}$ amplitude contribute to the rebound delay, we constructed generalized single and multicompartmental computational models of a midbrain dopamine neuron containing ionic conductances that approximated those recorded in our cells. The model enabled us to selectively alter only the time constant of $\mathrm{I}_{\mathrm{A}}$ inactivation while preserving the peak current amplitude, a manipulation that is not experimentally possible, and to generate a within-cell prediction of how this manipulation would influence rebound delays and GABAergic pauses. Figure $11 A$ shows traces of simulated A-type currents with inactivation decay time constants ranging from 25-200 ms in a single compartmental model of a dopamine neuron soma. We incorporated these conductances separately into the multicompartmental model and ran simulations of the rebound delay or inhibitory pauses as shown in the traces provided in Figure $11 B-D$.

Our first simulations tested the effect of slowing $\mathrm{I}_{\mathrm{A}}$ inactivation in a mesoaccumbal-like model cell with only a small amplitude IH (Fig. $11 B, C$ ). Consistent with the correlations from our experimental results, simulations of the mesoaccumbal-like model predicted that slowing the time constant of inactivation, while maintaining the peak current amplitude at a fixed value, is sufficient to lengthen the pause in firing following hyperpolarization. In particular, an inactivation time constant of $25 \mathrm{~ms}$ resulted in a rebound delay of $179.13 \mathrm{~ms}$, while a decay time constant of $200 \mathrm{~ms}$ resulted in a delay of $1.038 \mathrm{~s}$, about six times longer. Similarly, we tested the direct effects of changing inactivation kinetics of $\mathrm{I}_{\mathrm{A}}$ on the duration of pauses that follow GABAergic stimulation (Fig. 11D). We simulated a $50 \mathrm{~Hz}$ GABAergic stimulation (300 ms) onto a background of spontaneous firing in the model cell with inactivation decay values ranging from 25 to 200 ms. We found that for an $\mathrm{I}_{\mathrm{A}}$ decay time constant of $25 \mathrm{~ms}$, the spike-to-spike delay was $604.98 \mathrm{~ms}$, compared to $1.35 \mathrm{~s}$ for an $\mathrm{I}_{\mathrm{A}}$ time constant of $200 \mathrm{~ms}$ (Fig. 11D). As such, our model shows that the decay time constant of $\mathrm{I}_{\mathrm{A}}$ is a direct contributor to pauses that result from synaptic inhibition.

However, it is possible that a model cell with a relatively large IH amplitude (e.g., a nigrostriatal-like model) may be less affected by changes in the $\mathrm{I}_{\mathrm{A}}$ inactivation time constant. Interestingly, simulations of a nigrostriatal-like model neuron, which had a substantially larger IH (two or six times larger amplitude, as indicated by the prominent sag shown in Fig. $11 E$ ) were qualitatively similar to the model with a small $\mathrm{I}_{\mathrm{H}}(1 \times)$. We found that increasing the density of $\mathrm{I}_{\mathrm{H}}$ in the model cell speeded the rebound delay in a mesoaccumbal-like model neuron with $200 \mathrm{~ms} \mathrm{I}_{\mathrm{A}}$ inactivation time constant (Fig. 11E). Rebound delays for model cells with $\mathrm{I}_{\mathrm{H}}$ densities of 1,2 , and $6 \times$ were 1038.14 , 964.97, and $799.66 \mathrm{~ms}$. Therefore, increasing the density of $\mathrm{I}_{\mathrm{H}}$ by six times resulted in a reduction in the slope of the rebound delay versus inactivation time constant relationship (Fig. $11 F$ ). However, increasing the amplitude of $\mathrm{I}_{\mathrm{H}}$ did not abolish the effect of slowing inactivation on the rebound delay. In combination with the relative amplitude of $\mathrm{I}_{\mathrm{A}}$ and $\mathrm{I}_{\mathrm{H}}$, these simulations from our computational model support correlations from our experimental data that the kinetics of $\mathrm{I}_{\mathrm{A}}$ strongly regulate the timing of spikes following hyperpolarizing inhibition.

Midbrain dopamine neurons have been shown to express T-type calcium currents (Kang and Kitai, 1993; Wolfart and Roeper, 2002; Philippart et al., 2016), which are also activated in approximately the same voltage range as A-type potassium currents (Anderson et al., 2010). Therefore, we assessed the effect of T-type calcium currents on the rebound delay in our model neuron. Increasing the $\mathrm{T}$-type calcium conductance from $1 \times$ to $10 \times$ greater resulted in a decrease in the rebound delay for all $\mathrm{I}_{\mathrm{A}}$ inactivation time constants examined (Fig. $11 G, H$ ). However, we found that increasing T-type currents did not significantly alter the overall trend in our data. Therefore, our findings are consistent with the idea that T-type calcium currents contribute to shorter rebound delays, but are less effective in the presence of slowly inactivating $\mathrm{I}_{\mathrm{A}}$. Together, computational modeling and experimental results clearly demonstrate the role of slow inactivation kinetics of $\mathrm{I}_{\mathrm{A}}$ in shaping the rebound pause.

\section{Discussion}

Here, we show that mesoaccumbal and nigrostriatal dopamine neurons are distinguished by their sensitivity to inhibitory events ("rebound properties") resulting from differences in the intrinsic conductances that shape pauses. In particular, we found that mesoaccumbal neurons respond to hyperpolarizing current pulses with significantly longer delays in spiking relative to nigrostriatal neurons. The differences in the rebound delays were dependent upon the strength and duration of inhibitory pulses, with hyperpolarizations of $100 \mathrm{~ms}$ or longer evoking near maximal delays in both neuronal subpopulations. The ionic mechanism underlying longer delays in mesoaccumbal neurons is an inactivating A-type potassium current that decays slowly, along with weak expression of $\mathrm{H}$ currents. Computational modeling supports the idea that A-type potassium currents are recruited during rebound delays and synaptically evoked pauses to prolong pauses in a manner that strongly depends on the inactivation time constant of $\mathrm{I}_{\mathrm{A}}$. Together, our results demonstrate that $\mathrm{I}_{\mathrm{A}}$ shapes responses of dopamine neurons to GABAergic inhibitory inputs and suggest that the slow kinetics of IA result in heightened sensitivity of mesoaccumbal neurons to hyperpolarizing inhibition. We propose that these results may explain, in part, the observation that many dopamine neurons of the VTA and ventromedial SNc recorded in vivo exhibit robust pause responses to aversive stimuli 


\section{MA Example Neuron}

A

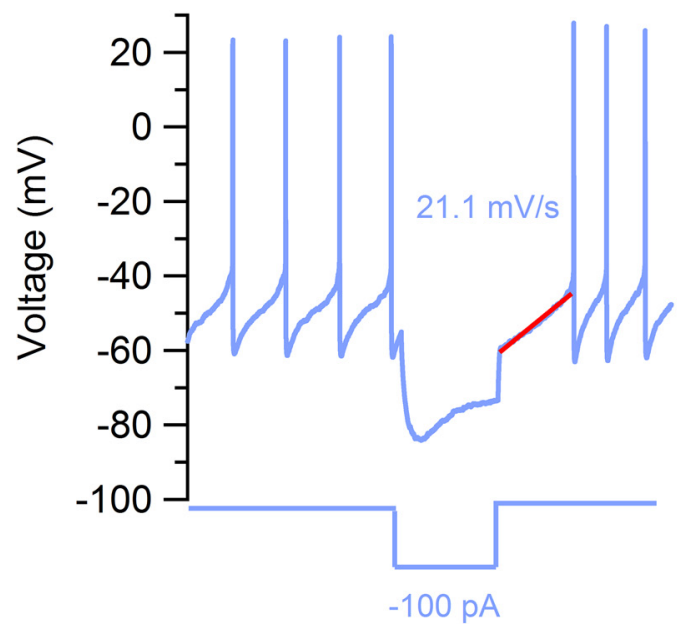

\section{Voltage Clamp}
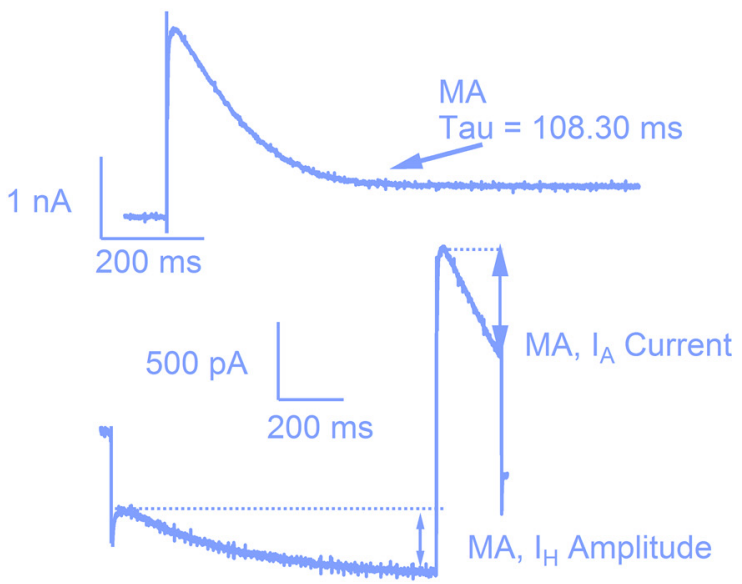

B

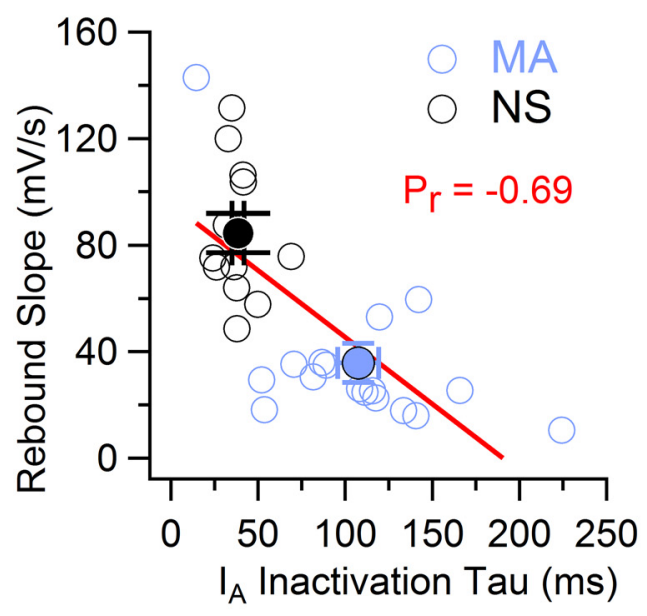

C

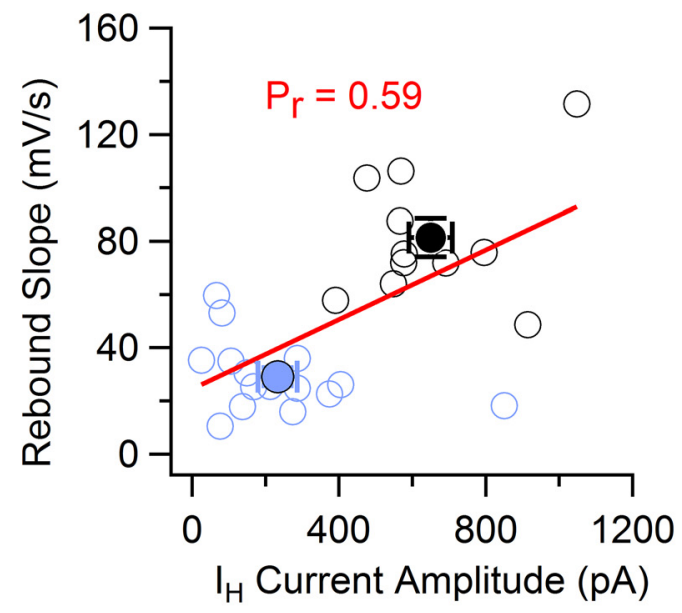

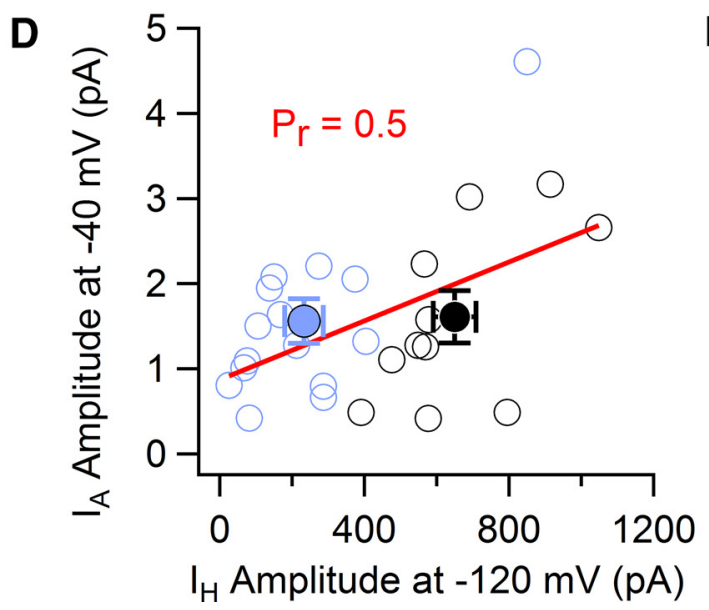

E

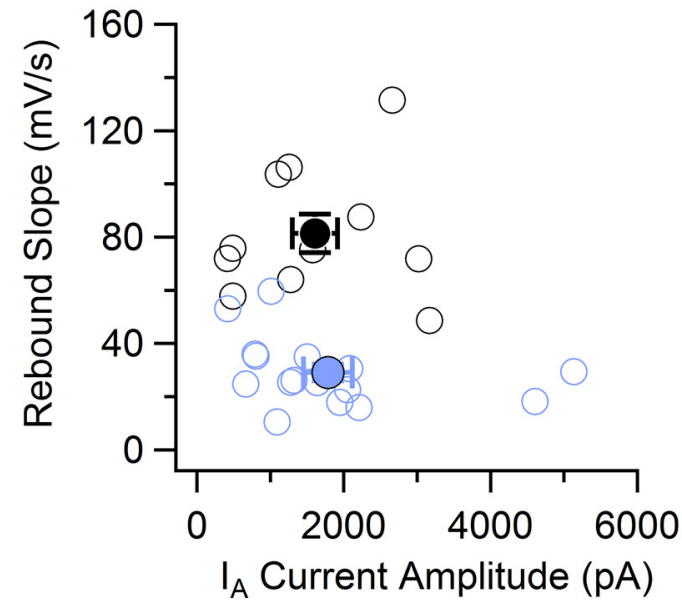

Figure 10. Correlation of inactivation kinetics of $\mathrm{I}_{\mathrm{A}}$ and the amplitude of $\mathrm{I}_{\mathrm{H}}$ with rebound properties in mesoaccumbal and nigrostrial dopamine neurons. $A$, Left, Example of rebound delay in mesoaccumbal (MA) dopamine neuron. The linear fit to determine the rebound slope is shown in red. Right, Voltage-clamp-recorded $I_{A}$ (top) and $I_{H}$ (bottom) currents from same neuron shown in A. A-type potassium currents were elicited by a step to $-40 \mathrm{mV}$ (top), and $I_{H}$ currents were measured from a step to $-120 \mathrm{mV}$. $B$, Plot of rebound slope versus $I_{A}$ inactivation time constant. Data from mesoaccumbal neurons are shown with light blue open symbols, and those from nigrostriatal (NS) neurons are shown with black open symbols. The linear fit to the data is shown in red along with Prvalues. Light blue and black closed symbols are average $\pm S E M$. C, Plot of rebound slope versus $I_{H}$ current amplitude. $D$, Plot of $I_{A}$ amplitude versus $I_{H}$ amplitude. $E$, Plot of rebound slope versus $\mathrm{I}_{\mathrm{A}}$ current amplitude. Note that the linear fit is not shown due to lack of correlation $(\mathrm{Pr}=-0.13)$. 


\section{Model DA Neuron}

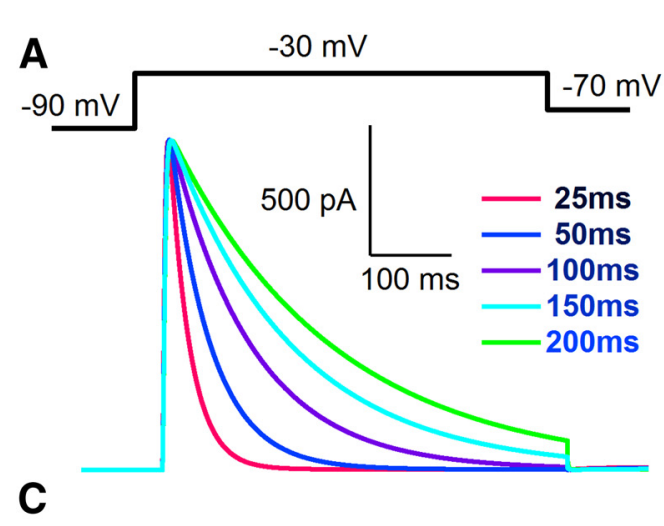

B

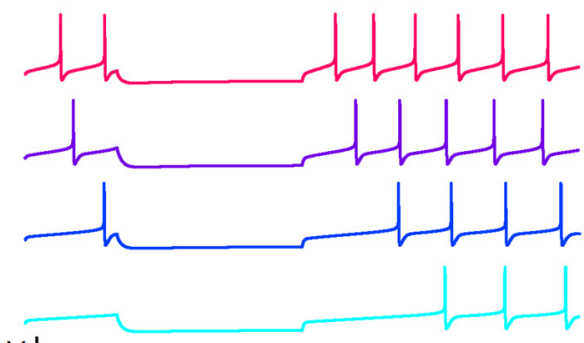

$40 \mathrm{mV}$
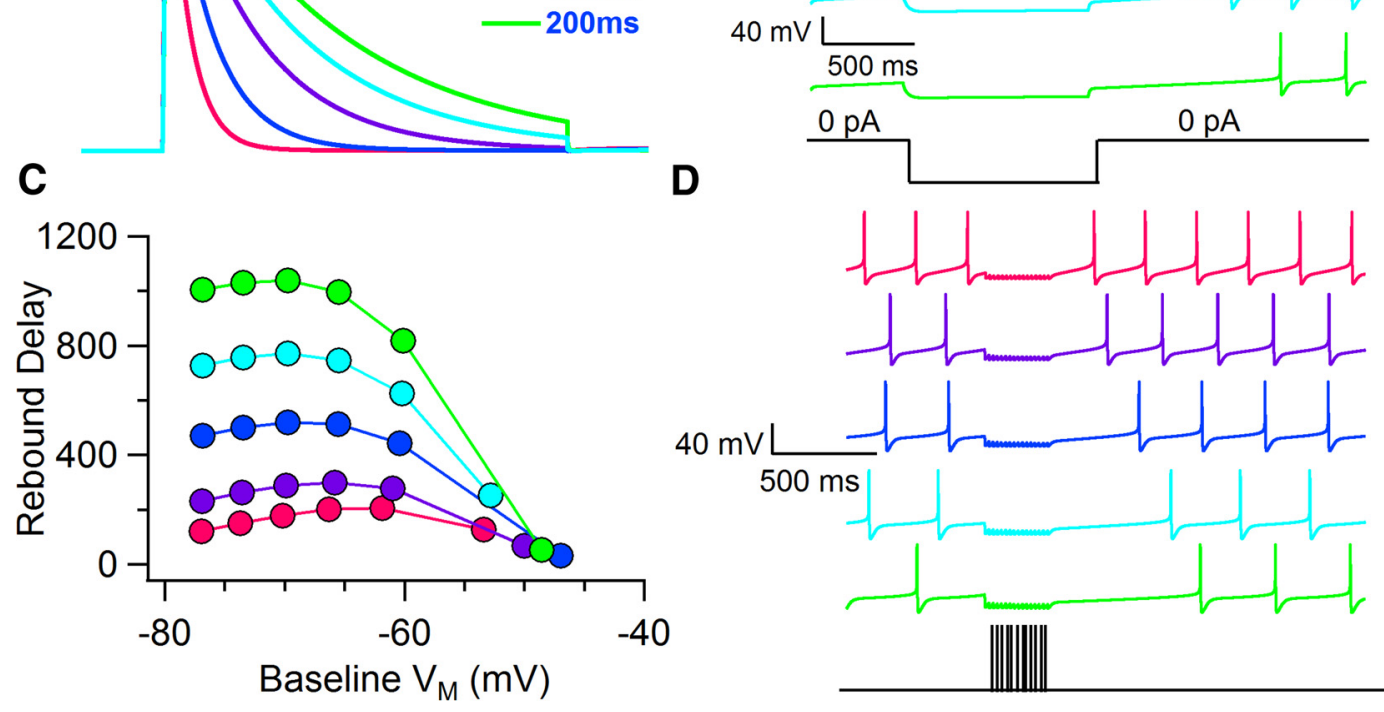

D

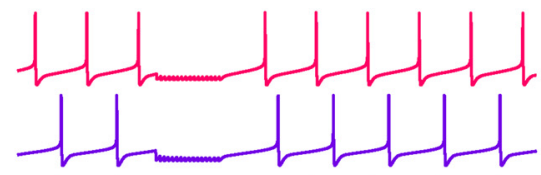

$40 \mathrm{mV}$
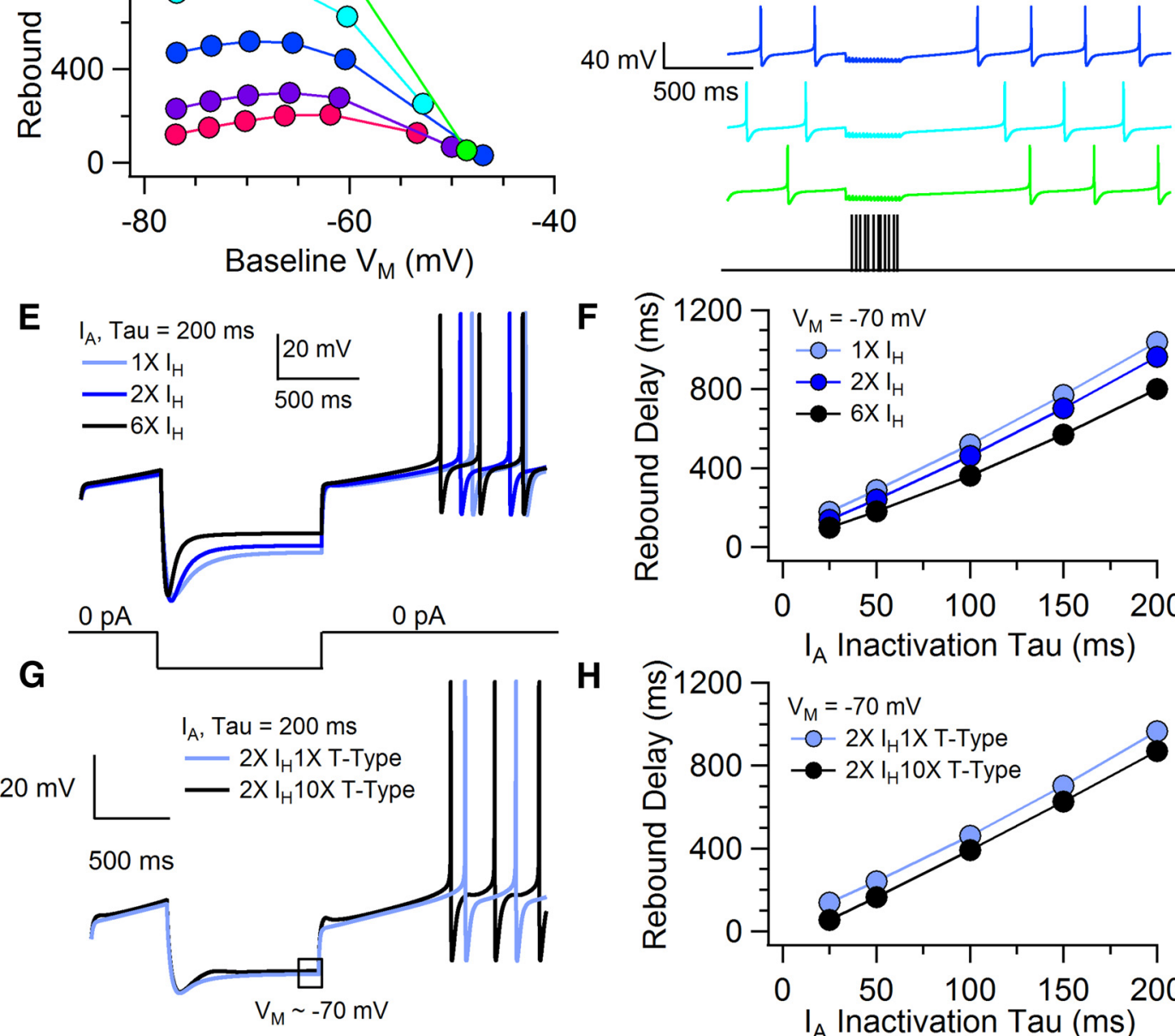

$\mathbf{F}$

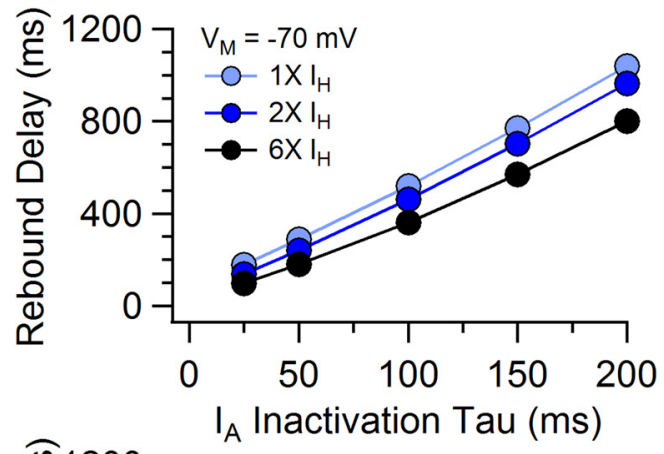

H

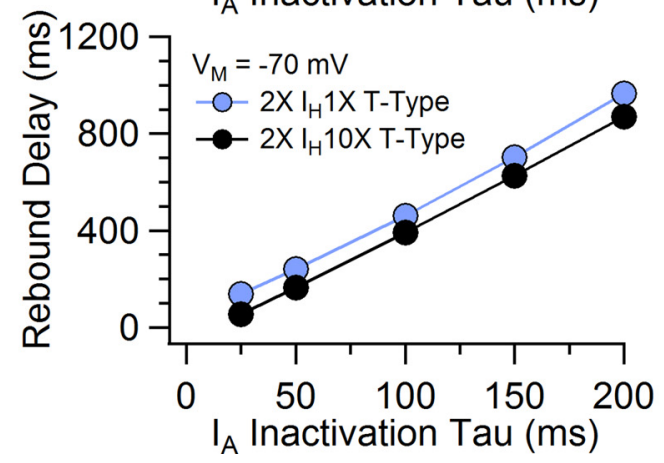

Figure 11. Computational model testing the relative contribution of $\mathrm{I}_{A^{\prime}} \mathrm{I}_{\mathrm{H}^{\prime}}$ and $\mathrm{I}_{T}$ to the rebound delay and $G A B A_{A}$-evoked pauses in firing. $A$, Traces of simulated $A$-type potassium currents covering the experimentally observed range of inactivation time constants from 25 to $200 \mathrm{~ms}$. $I_{A}$ currents were elicited by steps from -90 to $-30 \mathrm{mV}$. Important to note is that the model conductances were adjusted to offset changes in peak current amplitudes resulting from alteration of decay time constants. $\boldsymbol{B}$, Rebound delays increase in duration in models with slower $\mathrm{I}_{\mathrm{A}}$ inactivation kinetics. $C$, Voltage dependence of the rebound delay plotted in a model for $\mathrm{I}_{\mathrm{A}}$ time constant of inactivation ranging from 25 to $200 \mathrm{~ms}$. Note the increase in the rebound delay with increasing voltage and with increase in the inactivation tau of $\mathrm{I}_{A} \cdot D, G A B A_{A}$ evoked pauses increase in duration in models with slower $I_{A}$ inactivation kinetics. Simulated synaptic input was delivered at $50 \mathrm{~Hz}$ for $300 \mathrm{~ms}$. $\boldsymbol{E}$, Comparison voltage sags in three model neurons that range in relative peak conductance values of $\mathrm{I}_{H}$ from one to six times peak, using an $\mathrm{I}_{\mathrm{A}}$ tau value of $200 \mathrm{~ms}$. $\boldsymbol{F}$, Plot of inactivation time constant of $\mathrm{I}_{\mathrm{A}}$ versus rebound delays, measured from a baseline voltage of $-70 \mathrm{mV}$, in models with amplitudes of $\mathrm{I}_{H}$ ranging from one to six times the peak. $G$, Comparison of rebound delay in two model neurons where T-type calcium is present at our control permeability value and at 10 times that value, with $200 \mathrm{~ms}$ of $\mathrm{I}_{A}$ inactivation tau. Note the decrease in the rebound delay with $\mathrm{T}$-type calcium present. $\boldsymbol{H}$, Plot of rebound delay versus inactivation tau of $\mathrm{I}_{A}$ in the our model neuron where $\mathrm{T}$-type calcium current is present at our control permeability value (light blue circles) and 10 times that value (black circles). 
while dorsolateral $\mathrm{SNc}$ neurons exhibit much weaker responses (McHaffie et al., 2006; Brown et al., 2009; Matsumoto and Hikosaka, 2009; Lerner et al., 2015).

\section{Heterogeneity in $\mathrm{I}_{\mathrm{A}}$ inactivation kinetics: molecular mechanism}

Heterogeneity in $\mathrm{I}_{\mathrm{A}}$ inactivation kinetics has been observed in several neuronal types. Specifically, decay time constants ranging from 20 to $100 \mathrm{~ms}$, and even up to $300 \mathrm{~ms}$, have been observed in neurons of the nucleus of the tractus solitarii (Strube et al., 2015), tuberomammillary neurons (Jackson and Bean, 2007), globus pallidus and basal forebrain neurons (Baranauskas, 2004). Likewise, our data show a broad range of inactivation kinetics in mesoaccumbal neurons with many cells exhibiting atypically slow inactivating A-type potassium currents (average tau inactivation of mesoaccumbal neurons, $\sim 98 \mathrm{~ms}$ ), while mesostriatal neurons display a much narrower range of inactivating currents, consistent with data from unlabeled SNc dopamine neurons (Liss et al., 2001; Amendola et al., 2012). By contrast, A-type potassium currents found in the hippocampal CA1 pyramidal and most cerebellar granule neurons inactivate more quickly with decay time constants between 10 and 45 ms (Jerng et al., 2004; Kim et al., 2008).

The molecular mechanism of heterogeneity among A-type potassium currents has been examined both in heterologous expression systems and in a variety of neuronal cell types (Carrasquillo et al., 2012; Jerng and Pfaffinger, 2014). From these studies, several accessory subunits have been identified and shown both to influence channel density and to modulate the properties of A-type currents, including dipeptidyl peptidase (DPP) subunits (Nadal et al., 2003) as well as the Kv channel-interacting proteins (KChIPs; An et al., 2000; Ohya et al., 2001). A rigorous study of A-type currents in pyramidal neurons of the visual cortex using knock-out models and RNAi knockdown techniques found that KChIP2, KChIP3, and KChIP4 are necessary for the formation and expression of functional Kv4.2 channels (Norris et al., 2010). A separate study of globus pallidus and basal forebrain neurons found a correlation between the presence of KChIP4 subunit A mRNA and slowly inactivating A-type currents (up to $300 \mathrm{~ms}$ inactivation time constant; Baranauskas, 2004). These studies are consistent with results from expression systems showing that coexpression of KChIP1-4 with Kv4 subunits slows inactivation and speeds the recovery from inactivation (Patel et al., 2002; Gebauer et al., 2004; Jerng et al., 2005; Kitazawa et al., 2014).

In dopamine neurons, the molecular correlate of IA remains an important and open question. Past work in substantia nigra neurons has shown that the pore forming subunit, Kv4.3, exists within a complex with the long isoform of KChIP3 (Liss et al., 2001). Interestingly, analysis of a recently published data set profiling the total cellular RNA of dopaminergic neurons using translating ribosome affinity purification techniques (TRAPseq) in transgenic mice shows results that are consistent with this observation (Brichta et al., 2015) and in addition reveals high levels of mRNA fragments from DPP6, DPP10, KChIP1, KChIP3, and KChIP4 in samples from both VTA and SNc dopaminergic neurons. These data align in part with reports that $\mathrm{I}_{\mathrm{A}}$ inactivation is speeded in VTA dopamine neurons recorded in KChIP4 knock-out mice (Kashiotis, 2011), which also exhibit fewer and shorter duration pauses in behavioral experiments (Costa et al., 2014, 2016). Future work should address the role KChIPs and other Kv4 accessory subunits in modulating IA and further examine the effects of this modulation on the function of distinct dopamine neuron subpopulations.

\section{Diversity of pauses and underlying mechanisms in midbrain dopamine neurons}

The two main types of pauses that have been observed in dopamine neurons recorded from in vivo preparations are inhibitory pauses and postburst pauses. Unlike the findings from in vivo experiments (Clark and Chiodo, 1988), however, our data show that mesoaccumbal and nigrostriatal dopamine neurons exhibit almost identical postburst pauses. This observation suggests that the mechanisms that underlie postburst pauses may be distinct from those shaping inhibitory pauses. Postburst pauses may involve small-conductance, calcium-activated (SK) currents activated by increases in intracellular $\mathrm{Ca} 2+$ that result from highfrequency spiking or activation of metabotropic glutamate receptors (Fiorillo and Williams, 1998; Morikawa et al., 2003). In addition, it is likely that bursting neurons can experience pauses caused in part by $\mathrm{Na}^{+}$channel inactivation during the refractory period (Tucker et al., 2012). Inhibitory pauses are also initiated as well as maintained to some extent by synaptic or modulatory inputs (Fiorillo and Williams, 1998; Gantz et al., 2013). However, unlike postburst pauses, our data show that pauses evoked by synaptic inhibition involves far fewer intrinsic conductances and are dominated by $\mathrm{I}_{\mathrm{A}}$ and $\mathrm{I}_{\mathrm{H}}$, but also may involve T-type $\mathrm{Ca}^{2+}$ channels in a subset of SNc neurons (Evans and Khaliq, 2015). Therefore, the intrinsic conductances that differentiate pauses in mesoaccumbal and nigrostriatal neurons are valid for inhibitory pauses. The extent to which these conductances contribute to pauses evoked by excitation remains undetermined.

\section{Functional significance}

A number of recent studies in vivo have demonstrated physiological heterogeneity in responses to aversive stimuli that correlates with the anatomical position of cells within the midbrain. For example, a study of dopamine neurons in monkeys reported that dorsolateral tier SNc neurons (dorsal striatum projecting) increase their firing in response to aversion, while ventromedial $\mathrm{SNc}$ and VTA neurons (ventral striatum projecting) pause their activity (Matsumoto and Hikosaka, 2009). In a separate study in mice, intracellular $\mathrm{Ca} 2+$ signals recorded in response to aversive stimuli were enhanced in dorsolateral striatum projecting dopamine neurons but inhibited in ventromedial striatum projecting neurons (Lerner et al., 2015). Similarly, other studies have shown that aversive stimuli result in either short-latency pauses or only weakly reduce firing in SNc neurons (Brown et al., 2009), but result in long-latency aversive pauses in VTA dopamine neurons (Mileykovskiy and Morales, 2011). While these studies establish that diversity exists in aversive responses among dopamine neurons, our results provide insight into the underlying cellular mechanisms. To build upon our findings of diversity in integration of inhibitory inputs, it will be important for future experiments performed in vitro and in vivo to examine features of synaptic inputs, including determining activity patterns of presynaptic neurons and synaptic weights that contribute to overall functional heterogeneity among dopamine neurons.

\section{References}

Amendola J, Woodhouse A, Martin-Eauclaire MF, Goaillard JM (2012) $\mathrm{Ca}(2)(+) / c$ AMP-sensitive covariation of $\mathrm{I}(\mathrm{A})$ and $\mathrm{I}(\mathrm{H})$ voltage dependences tunes rebound firing in dopaminergic neurons. J Neurosci 32 : 2166-2181. CrossRef Medline

An WF, Bowlby MR, Betty M, Cao J, Ling HP, Mendoza G, Hinson JW, Mattsson KI, Strassle BW, Trimmer JS, Rhodes KJ (2000) Modulation of A-type potassium channels by a family of calcium sensors. Nature 403: 553-556. CrossRef Medline

Anderson D, Rehak R, Hameed S, Mehaffey WH, Zamponi GW, Turner RW 
(2010) Regulation of the KV4.2 complex by CaV3.1 calcium channels. Channels 4:163-167. CrossRef Medline

Aransay A, Rodríguez-López C, García-Amado M, Clascá F, Prensa L (2015) Long-range projection neurons of the mouse ventral tegmental area: a single-cell axon tracing analysis. Front Neuroanat 9:59. Medline

Baranauskas G (2004) Cell-type-specific splicing of KChIP4 mRNA correlates with slower kinetics of A-type current. Eur J Neurosci 20:385-391. CrossRef Medline

Beier KT, Steinberg EE, DeLoach KE, Xie S, Miyamichi K, Schwarz L, Gao XJ, Kremer EJ, Malenka RC, Luo L (2015) Circuit architecture of VTA dopamine neurons revealed by systematic input-output mapping. Cell 162 : 622-634. CrossRef Medline

Björklund A, Dunnett SB (2007) Dopamine neuron systems in the brain: an update. Trends Neurosci 30:194-202. CrossRef Medline

Bower JM, Beeman D (2007) Constructing realistic neural simulations with GENESIS. Methods Mol Biol 401:103-125. CrossRef Medline

Brichta L, Shin W, Jackson-Lewis V, Blesa J, Yap EL, Walker Z, Zhang J, Roussarie JP, Alvarez MJ, Califano A, Przedborski S, Greengard P (2015) Identification of neurodegenerative factors using translatome-regulatory network analysis. Nat Neurosci 18:1325-1333. CrossRef Medline

Brown MT, Henny P, Bolam JP, Magill PJ (2009) Activity of neurochemically heterogeneous dopaminergic neurons in the substantia nigra during spontaneous and driven changes in brain state. J Neurosci 29:2915-2925. CrossRef Medline

Carrasquillo Y, Burkhalter A, Nerbonne JM (2012) A-type K+ channels encoded by Kv4.2, Kv4.3 and Kv1.4 differentially regulate intrinsic excitability of cortical pyramidal neurons. J Physiol 590:3877-3890. CrossRef Medline

Clark D, Chiodo LA (1988) Electrophysiological and pharmacological characterization of identified nigrostriatal and mesoaccumbens dopamine neurons in the rat. Synapse 2:474-485. CrossRef Medline

Cohen JY, Haesler S, Vong L, Lowell BB, Uchida N (2012) Neuron-typespecific signals for reward and punishment in the ventral tegmental area. Nature 482:85-88. CrossRef Medline

Costa KM, Subramaniam M, Kashiotis AM, Schneider G, Roeper J (2014) Selective dynamic range compression of in vivo firing of dopamine VTA neurons in KChIP4 knockout mice. Soc Neurosci Abstr 40:299.19/B43.

Costa KM, Kashiotis AM, Schneider G, Subramaniam M, Roeper J (2016) KChIP4: a biophysical amplifier of inhibition in mesolimbic dopamine neurons. Soc Neurosci Abstr 42:167.16/AAA10.

Dahlstroem A, Fuxe K (1964) Evidence for the existence of monoaminecontaining neurons in the central nervous system. I. Demonstration of monoamines in the cell bodies of brain stem neurons. Acta Physiol Scand Suppl 232:231-255. Medline

Edwards NJ, Tejeda HA, Pignatelli M, Zhang S, McDevitt RA, Wu J, Bass CE, Bettler B, Morales M, Bonci A (2017) Circuit specificity in the inhibitory architecture of the VTA regulates cocaine-induced behavior. Nat Neurosci 20:438-448. CrossRef Medline

Evans RC, Polavaram S (2013) Growing a garden of neurons. Front Neuroinform 7:17. CrossRef Medline

Evans RC, Khaliq ZM (2015) T-type calcium channels control nonlinear dendritic integration in vulnerable subpopulation of substantia nigra dopamine neurons. Soc Neurosci Abstr 41:801.03/R6.

Fallon JH, Moore RY (1978) Catecholamine innervation of the basal forebrain. IV. Topography of the dopamine projection to the basal forebrain and neostriatum. J Comp Neurol 180:545-580. CrossRef Medline

Fiorillo CD, Song MR, Yun SR (2013a) Multiphasic temporal dynamics in responses of midbrain dopamine neurons to appetitive and aversive stimuli. J Neurosci 33:4710-4725. CrossRef

Fiorillo CD, Yun SR, Song MR (2013b) Diversity and homogeneity in responses of midbrain dopamine neurons. J Neurosci 33:4693-4709. CrossRef Medline

Fiorillo CD, Williams JT (1998) Glutamate mediates an inhibitory postsynaptic potential in dopamine neurons. Nature 394:78-82. CrossRef Medline

Gantz SC, Bunzow JR, Williams JT (2013) Spontaneous inhibitory synaptic currents mediated by a G protein-coupled receptor. Neuron 78:807-812. CrossRef Medline

Gebauer M, Isbrandt D, Sauter K, Callsen B, Nolting A, Pongs O, Bähring R (2004) N-type inactivation features of Kv4.2 channel gating. Biophys J 86:210-223. CrossRef Medline

Gentet LJ, Williams SR (2007) Dopamine gates action potential backpropa- gation in midbrain dopaminergic neurons. J Neurosci 27:1892-1901. CrossRef Medline

Hirschberg B, Maylie J, Adelman JP, Marrion NV (1998) Gating of recombinant small-conductance Ca-activated $\mathrm{K}+$ channels by calcium. J Gen Physiol 111:565-581. CrossRef Medline

Jackson AC, Bean BP (2007) State-dependent enhancement of subthreshold A-type potassium current by 4-aminopyridine in tuberomammillary nucleus neurons. J Neurosci 27:10785-10796. CrossRef Medline

Jaffe DB, Wang B, Brenner R (2011) Shaping of action potentials by type I and type II large-conductance $\mathrm{Ca}(2)+$-activated $\mathrm{K}+$ channels. Neuroscience 192:205-218. CrossRef Medline

Jerng HH, Pfaffinger PJ (2014) Modulatory mechanisms and multiple functions of somatodendritic A-type $\mathrm{K}(+)$ channel auxiliary subunits. Front Cell Neurosci 8:82. Medline

Jerng HH, Pfaffinger PJ, Covarrubias M (2004) Molecular physiology and modulation of somatodendritic A-type potassium channels. Mol Cell Neurosci 27:343-369. CrossRef Medline

Jerng HH, Kunjilwar K, Pfaffinger PJ (2005) Multiprotein assembly of Kv4.2, KChIP3 and DPP10 produces ternary channel complexes with ISA-like properties. J Physiol 568:767-788. CrossRef Medline

Kang Y, Kitai ST (1993) A whole cell patch-clamp study on the pacemaker potential in dopaminergic neurons of rat substantia nigra compacta. Neurosci Res 18:209-221. CrossRef Medline

Kashiotis AM, Krabbe S, Lammel S, Liss B, Roeper J (2011) The differential role of KChIP4The differential role of KChIP4 subunits for native A-type potassium currents in distinct subpopulations of dopaminergic midbrain neurons. In: Neuroscience: The annual meeting for the Society for Neuroscience, Washington DC, November.

Khaliq ZM, Bean BP (2008) Dynamic, nonlinear feedback regulation of slow pacemaking by A-type potassium current in ventral tegmental area neurons. J Neurosci 28:10905-10917. CrossRef Medline

Kim J, Nadal MS, Clemens AM, Baron M, Jung SC, Misumi Y, Rudy B, Hoffman DA (2008) Kv4 accessory protein DPPX (DPP6) is a critical regulator of membrane excitability in hippocampal CA1 pyramidal neurons. J Neurophysiol 100:1835-1847. CrossRef Medline

Kitazawa M, Kubo Y, Nakajo K (2014) The stoichiometry and biophysical properties of the Kv4 potassium channel complex with $\mathrm{K}+$ channelinteracting protein (KChIP) subunits are variable, depending on the relative expression level. J Biol Chem 289:17597-17609. CrossRef Medline

Koyama S, Appel SB (2006) A-type K+ current of dopamine and GABA neurons in the ventral tegmental area. J Neurophysiol 96:544-554. CrossRef Medline

Lerner TN, Shilyansky C, Davidson TJ, Evans KE, Beier KT, Zalocusky KA, Crow AK, Malenka RC, Luo L, Tomer R, Deisseroth K (2015) IntactBrain Analyses Reveal Distinct Information Carried by SNc Dopamine Subcircuits. Cell 162:635-647. CrossRef Medline

Liss B, Franz O, Sewing S, Bruns R, Neuhoff H, Roeper J (2001) Tuning pacemaker frequency of individual dopaminergic neurons by Kv4.3L and KChip3.1 transcription. EMBO J 20:5715-5724. CrossRef Medline

Liu P, Jo S, Bean BP (2012) Modulation of neuronal sodium channels by the sea anemone peptide BDS-I. J of neurophysiology 107:3155-3167. CrossRef Medline

Matsumoto M, Hikosaka O (2009) Two types of dopamine neuron distinctly convey positive and negative motivational signals. Nature 459: 837-841. CrossRef Medline

Matsushita N, Okada H, Yasoshima Y, Takahashi K, Kiuchi K, Kobayashi K (2002) Dynamics of tyrosine hydroxylase promoter activity during midbrain dopaminergic neuron development. J Neurochem 82:295-304. CrossRef Medline

Maylie J, Bond CT, Herson PS, Lee WS, Adelman JP (2004) Small conductance Ca2+-activated $\mathrm{K}+$ channels and calmodulin. J Physiol 554:255261.

McHaffie JG, Jiang H, May PJ, Coizet V, Overton PG, Stein BE, Redgrave P (2006) A direct projection from superior colliculus to substantia nigra pars compacta in the cat. Neuroscience 138:221-234. CrossRef Medline

Menegas W, Bergan JF, Ogawa SK, Isogai Y, Umadevi Venkataraju K, Osten P, Uchida N, Watabe-Uchida M (2015) Dopamine neurons projecting to the posterior striatum form an anatomically distinct subclass. Elife 4:e10032. Medline

Migliore M, Cannia C, Canavier CC (2008) A modeling study suggesting a possible pharmacological target to mitigate the effects of ethanol on 
reward-related dopaminergic signaling. J Neurophysiol 99:2703-2707. CrossRef Medline

Mileykovskiy B, Morales M (2011) Duration of inhibition of ventral tegmental area dopamine neurons encodes a level of conditioned fear. J Neurosci 31:7471-7476. CrossRef Medline

Morikawa H, Khodakhah K, Williams JT (2003) Two intracellular pathways mediate metabotropic glutamate receptor-induced $\mathrm{Ca} 2+$ mobilization in dopamine neurons. J Neurosci 23:149-157. Medline

Nadal MS, Ozaita A, Amarillo Y, Vega-Saenz de Miera E, Ma Y, Mo W, Goldberg EM, Misumi Y, Ikehara Y, Neubert TA, Rudy B (2003) The CD26-related dipeptidyl aminopeptidase-like protein DPPX is a critical component of neuronal A-type K+ channels. Neuron 37:449-461. CrossRef Medline

Neuhoff H, Neu A, Liss B, Roeper J (2002) I(h) channels contribute to the different functional properties of identified dopaminergic subpopulations in the midbrain. J Neurosci 22:1290-1302. Medline

Norris AJ, Foeger NC, Nerbonne JM (2010) Neuronal voltage-gated K+ $(\mathrm{Kv})$ channels function in macromolecular complexes. Neurosci Lett 486: 73-77. CrossRef Medline

Oades RD, Halliday GM (1987) Ventral tegmental (A10) system: neurobiology. 1. Anatomy and connectivity. Brain Res 434:117-165. Medline

Ohya S, Tanaka M, Oku T, Furuyama T, Mori N, Giles WR, Watanabe M, Imaizumi Y (2001) Regional expression of the splice variants of Kv4.3 in rat brain and effects of $\mathrm{C}$-terminus deletion on expressed $\mathrm{K}+$ currents. Life Sci 68:1703-1716. CrossRef Medline

Patel SP, Campbell DL, Morales MJ, Strauss HC (2002) Heterogeneous expression of KChIP2 isoforms in the ferret heart. J Physiol 539:649-656. CrossRef Medline

Philippart F, Destreel G, Merino-Sepúlveda P, Henny P, Engel D, Seutin V (2016) Differential somatic $\mathrm{Ca} 2+$ channel profile in midbrain dopaminergic neurons. J Neurosci 36:7234-7245. CrossRef Medline
Schultz W, Dayan P, Montague PR (1997) A neural substrate of prediction and reward. Science 275:1593-1599. CrossRef Medline

Seutin V, Engel D (2010) Differences in $\mathrm{Na}+$ conductance density and $\mathrm{Na}+$ channel functional properties between dopamine and GABA neurons of the rat substantia nigra. J Neurophysiol 103:3099-3114. CrossRef Medline

Strube C, Saliba L, Moubarak E, Penalba V, Martin-Eauclaire MF, Tell F, Clerc N (2015) Kv4 channels underlie A-currents with highly variable inactivation time courses but homogeneous other gating properties in the nucleus tractus solitarii. Pflugers Arch 467:789-803. CrossRef Medline

Tepper JM, Lee CR (2007) GABAergic control of substantia nigra dopaminergic neurons. Prog Brain Res 160:189-208. CrossRef Medline

Tucker KR, Huertas MA, Horn JP, Canavier CC, Levitan ES (2012) Pacemaker rate and depolarization block in nigral dopamine neurons: a somatic sodium channel balancing act. J Neurosci 32:14519-14531. CrossRef Medline

Tuckwell HC (2012) Quantitative aspects of L-type Ca2+ currents. Prog Neurobiol 96:1-31. CrossRef Medline

Ungless MA, Magill PJ, Bolam JP (2004) Uniform inhibition of dopamine neurons in the ventral tegmental area by aversive stimuli. Science 303: 2040-2042. CrossRef Medline

Vacher H, Alami M, Crest M, Possani LD, Bougis PE, Martin-Eauclaire MF (2002) Expanding the scorpion toxin alpha-KTX 15 family with AmmTX3 from Androctonus mauretanicus. Eur J Biochem 269:6037-6041. CrossRef Medline

Wang DV, Tsien JZ (2011) Convergent processing of both positive and negative motivational signals by the VTA dopamine neuronal populations. PLoS One 6:e17047. CrossRef Medline

Wolfart J, Roeper J (2002) Selective coupling of T-type calcium channels to SK potassium channels prevents intrinsic bursting in dopaminergic midbrain neurons. J Neurosci 22:3404-3413. Medline 